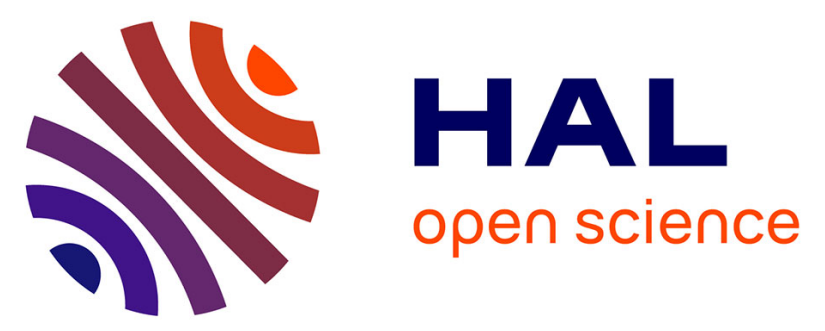

\title{
Assessing the impacts on fetal dosimetry of the modelling of the placental transfers of xenobiotics in a pregnancy physiologically based pharmacokinetic model
}

Marc Codaccioni, Céline Brochot

\section{- To cite this version:}

Marc Codaccioni, Céline Brochot. Assessing the impacts on fetal dosimetry of the modelling of the placental transfers of xenobiotics in a pregnancy physiologically based pharmacokinetic model. Toxicology and Applied Pharmacology, 2020, 409, pp.115318. 10.1016/j.taap.2020.115318 . ineris03318332

\section{HAL Id: ineris-03318332}

https://hal-ineris.archives-ouvertes.fr/ineris-03318332

Submitted on 9 Aug 2021

HAL is a multi-disciplinary open access archive for the deposit and dissemination of scientific research documents, whether they are published or not. The documents may come from teaching and research institutions in France or abroad, or from public or private research centers.
L'archive ouverte pluridisciplinaire $\mathbf{H A L}$, est destinée au dépôt et à la diffusion de documents scientifiques de niveau recherche, publiés ou non, émanant des établissements d'enseignement et de recherche français ou étrangers, des laboratoires publics ou privés. 


\title{
Assessing the impacts on fetal dosimetry of the modelling
}

\section{of the placental transfers of xenobiotics in a pregnancy}

\section{physiologically based pharmacokinetic model}

\author{
Marc Codaccioni ${ }^{*}$, Céline Brochot ${ }^{*}$.
}

*Models for Ecotoxicology and Toxicology unit (DRC/VIVA/METO), Institut National de l'Environnement Industriel et des Risques, 60550 Verneuil-en-Halatte, France.

${ }^{\dagger}$ Corresponding author; Tel: +333 445568 50; e-mail: celine.brochot@ineris.fr 


\begin{abstract}
The developmental origin of health and diseases theory support the critical role of the fetal exposure to children's health. We developed a physiologically based pharmacokinetic model for human pregnancy (pPBPK) to simulate the maternal and fetal dosimetry throughout pregnancy. Four models of the placental exchanges of chemicals were assessed on ten chemicals for which maternal and fetal data were available. These models were calibrated using non-animal methods: in vitro (InV) or ex vivo (ExV) data, a semi-empirical equation $(S E)$, or the limitation by the placental perfusion $(P L)$. They did not impact the maternal pharmacokinetics but provided different profiles in the fetus. The $P L$ and $\operatorname{In} V$ models performed well even if the $P L$ model overpredicted the fetal exposure for some substances. The $S E$ and $E x V$ models showed the lowest global performance and the $S E$ model a tendency to underprediction. The comparison of the profiles showed that the $P L$ model predicted an increase in the fetal exposure with the pregnancy age, whereas the $E x V$ model predicted a decrease. For the $S E$ and $\operatorname{In} V$ models, a small decrease was predicted during the second trimester. All models but the ExV one, presented the highest fetal exposure at the end of the third trimester. Global sensitivity analyses highlighted the predominant influence of the transfer constants on the fetal exposure, as well as the metabolic clearance and the fraction unbound. Finally, the four transfer models could be considered depending on the framework of the use of the pPBPK model and the availability of data or resources to inform their parametrization.
\end{abstract}

Key words: Physiologically based pharmacokinetic model, pregnancy, placental transfer, fetal exposure, chemicals, drugs. 


\section{INTRODUCTION}

The exposome concept calls for measuring the environmental component of diseases' etiology "from the prenatal period onwards" (Wild 2005). Assessing xenobiotic's exposure, as part of the specific external exposome (e.g., diet, smoking, drugs, environmental pollutants etc.), is essential since hazardous chemicals in food, drinking water, consumer products and ambient or household air pollution are strongly suspected to impact human health (European Environment Agency, 2019; Sunderland et al. 2019). Specific concerns warrant to focus efforts on the sensitive populations such as pregnant women and their developing fetuses (Rager et al. 2020). The prenatal life has been identified as a potential window of susceptibility to environmental pollutants exposure leading to postnatal short term (Philippat et al. 2012), congenital defects (Clayton-Smith et al. 2019) and even to later life disease (Haugen et al. 2015).

Diverse prospective and birth cohort studies such as MoBa (Magnus et al. 2016), HELIX (Maitre et al. 2018; Tamayo-Uria et al. 2019), ELFE (Vandentorren et al. 2009), or PELAGIE (Chevrier et al. 2011) have contributed to inform the prenatal exposome. The studies based on mother-child pairs aimed to identify associations between in utero exposure to environmental pollutants and increased risk for health outcomes in offspring (Rappazzo, Coffman, and Hines 2017; Rivollier, Krebs, and Kebir 2019). Since fetal blood sampling is not an option during pregnancy without clinical indication, fetal exposure is often estimated via the maternal concentrations throughout pregnancy or the cord blood concentrations at delivery. Pregnancy physiologically based pharmacokinetic (pPBPK) models can be used to simulate indicators of fetal exposure, such as the cumulated exposure or the maximal concentration in plasma or target sites of toxicity (Brochot et al. 2019). Those mechanistic models aim to describe the processes that a substance will undergo in the maternal and fetal bodies such as its absorption, distribution, metabolism and elimination. They can simulate the concentration time-course of a substance in various maternal and fetal organs and body fluids (Luecke et al. 1994).

Numerous pPBPK models for a compound (e.g., Lumen, Mattie, and Fisher 2013) or different chemical families (e.g., Beaudouin, Micallef, and Brochot 2010) have been published. Recently, we reviewed the published pPBPK models with a focus on the modelling of the placental exchanges 
(Codaccioni, Bois, and Brochot 2019). Our review showed the heterogeneity of the methodologies employed in pPBPK models to describe the placental transfers of xenobiotics, either for the placental structure or the parameterization of the transfer itself. Animal in vivo data are mainly used for placental transfer parameterization but several non-animal methods (e.g., in silico, in vitro, ex vivo) can also be used to estimate the placental transfers. For instance, the simplest approach consists in considering that the exchanges between the mother and the fetus are limited only by the rate of blood perfusion inflowing the placenta (Valcke and Krishnan 2011). Other approaches rely on an exchange rate extrapolated from the ex vivo cotyledon perfusion experiment (De Sousa Mendes et al. 2016), or from an intrinsic permeability computed either by a semi-empirical equation (Dallmann, Ince, Solodenko, et al. 2017) or by the ratio of apparent permeabilities taken from an in vitro system (Zhang and Unadkat 2017). Recently these three approaches were implemented in a pPBPK model and tested for acetaminophen (Mian et al. 2020), emtricitabine and acyclovir (Liu et al. 2020). Both studies showed that fetal internal dosimetry was impacted at term by the modelling of the placental exchanges and that the model predictive performance associated with those parameterizations varied between substances.

In this study, we aimed at extending these works by assessing the predictive performance of four non-animal methods to inform the chemical placental exchanges within a pPBPK model at different periods of pregnancy. First, we developed a pPBPK model which can predict the prenatal internal exposure during pregnancy. This new pPBPK model was adapted from the adult model available in the R package httk which was developed to support high throughput screening (Pearce et al. 2017). Our pPBPK model integrates physiological (volumes, blood flows, glomerular filtration rate etc.) and biochemical (enzyme activities, plasmatic protein concentrations etc.) changes associated with pregnancy in the mother and the fetus. Four approaches were tested for the placental transfer parameterization (perfusion limited transfer or diffusion limited transfer with ex vivo, in vitro or in silico data) in order to assess i) their predictive performance on a set of ten substances with in vivo maternal and fetal concentrations measured at different periods of pregnancy ; and ii)their impacts on 
fetal internal dosimetry during pregnancy. Additionally, we conducted a global sensitivity analysis to study the influence of the model's parameters on the fetal dosimetry.

\section{MATERIAL AND METHODS}

\section{Model structure}

The pPBPK model associates two sub-models, one for the mother and one for the fetus (Figure 1). Their structures are both based on the PBPK model included in the R package httk (Pearce et al. 2017) which comprises five perfused compartments (lungs, gut, liver, kidneys and the rest of the body) and a non-perfused compartment (gut lumen) for oral dosing. We extended the maternal model with two new compartments related to tissues that evolve during pregnancy (i.e., adipose, mammary tissues). In fetus, lungs were not considered, and brain was added. The circulatory blood system was adapted to the fetus' physiology: $30 \%$ of the blood flow exiting the placenta by the umbilical cord vein is shunted to the fetal venous blood system through the ductus venosus, the remaining $70 \%$ reaches the fetal liver through the portal sinus. The placenta links the maternal and fetal sub-models and was modelled differently regarding the placental transfers models (see Modelling of the placental exchanges of substances section).

In the mother and fetus, the compound's distribution in the body is managed by the blood flow and the partitioning into tissues. A homogenous distribution was assumed in each maternal and fetal compartment, i.e., the compound's concentration was assumed to be the same in each compartment/tissue's region (e.g., in plasma and in interstitial and intercellular spaces). The general tissue mass balance equation was expressed as follows:

$\frac{d Q_{T}}{d t}=F_{T} \times\left(C_{a r t}-\frac{Q_{T}}{P C_{t: b} \times V_{T}}\right)$

with $F_{T}$ the inflowing blood flow (in L/min), $C_{a r t}$ the substance arterial blood concentration $(\mathrm{mg} / \mathrm{L}), Q_{T}$ the substance amount in tissue (mg), $V_{T}$ the tissue volume (L), and $P C_{t: b}$ the tissue to blood partition coefficient. 
The maternal model includes elimination pathways in the kidneys, venous blood and liver, accounting for urinary excretion and metabolism. Excreted or metabolized amounts were computed from the unbound plasma concentration. Depending on the substance considered, the urinary excretion was included either in the kidneys as the glomerular filtration rate $\left(F_{G F R}\right)$ (Eq. 2$)$ or in the venous blood as a plasmatic clearance scaled to $F_{G F R}$ changes during pregnancy (Eq. 3):

RateOfExcretion $=F_{G F R} \times$ Fup pgcy $\times \frac{C_{k i d}}{P C_{k: p}}(2)$

or,

RateOfExcretion $=C L_{r} \times \frac{F_{G F R}}{F_{G F R_{0}}} \times$ Fup pgcy $\times C_{\text {plas }}$

where $C L_{r}$ stands for the non-pregnant renal clearance $(\mathrm{L} / \mathrm{min}), F_{G F R}$ the glomerular filtration rate $(\mathrm{L} / \mathrm{min}), F_{\text {GFRO }}$ the non-pregnant glomerular filtration rate $(\mathrm{L} / \mathrm{min}), F u p_{p g c y}$ the maternal plasma fraction unbound during pregnancy, $C_{k i d}$ and $C_{\text {plas }}$ the concentrations in the kidneys and venous plasma (mg/L) respectively, and $P C_{k: p}$ the partition coefficient between kidneys and plasma.

Hepatic metabolism was assumed to be linear with dose:

RateOfMetabolism $=C L_{m e t} \times E n z_{v a r} \times F u p_{p g c y} \times \frac{C_{l i v}}{P C_{l: p}}$

where $C L_{m e}, C_{l i v}$ and $P C_{l: p}$ represent the non-pregnant metabolic clearance, the concentration in the liver and the liver:plasma partition coefficient, respectively. In order to account for the induction or inhibition of the metabolism observed during pregnancy, the rate of metabolism was made proportional to the variations of several hepatic enzyme activities during pregnancy as proposed by Dallmann, Ince, et al. (2018):

$$
\begin{aligned}
& E n z_{\text {var }}=f m_{2 D 6} \times C Y P_{2 A 6}+f m_{3 A} \times C Y P_{3 A}+f m_{1 A} \times C Y P_{1 A}+f m_{2 C 19} \times C Y P_{2 C 19}+f m_{2 C 9} \times \\
& C Y P_{2 C 9}+f m_{2 E 1} \times C Y P_{2 E 1}+f m_{2 B 6} \times C Y P_{2 B 6}+f m_{2 A 6} \times C Y P_{2 A 6}+f m_{\text {other }}
\end{aligned}
$$

with $f m_{x x}$ the dose fraction of a compound metabolized through a specific pathway $(x x)$ and $C Y P_{x x}$ the changes in activity for this specific enzyme pathway. The equations and the related profiles describing the changes in enzymes activities during pregnancy (Dallmann, Ince, et al. 2018; Abduljalil et al. 
2012) are presented in Supplemental Material (Figure S1). It should be highlighted this methodology is only accurate in case of linear metabolism as assumed in Equation 4.

The fetal sub-model does not include urinary excretion or metabolism. The fetal intake and elimination were then only driven by the placental exchanges between the mother and the fetus.

\section{Modelling of the placental exchanges of substances}

Two hypotheses on the placental structure were tested to model the bidirectional transfers of compounds through the placenta during pregnancy. The transfers were modeled either by blood perfusion (i.e., a unique placental compartment perfused by both maternal and fetal blood) or by diffusion (i.e., the placenta is divided into two sub-compartments linked by a diffusion parameter). In the first case, the placental compartment is defined as follows:

$$
\frac{d Q_{\text {plac }}}{d t}=F_{\text {plac }_{m}} \times C_{\text {art }}+F_{\text {plac }_{f}} \times C_{\text {art }_{f}}-\left(F_{\text {plac }_{m}}+F_{\text {plac }_{f}}\right) \times \frac{C_{\text {plac }}}{P C_{\text {plac }: b}}
$$

When the transfers are limited by diffusion, the maternal and fetal placental amounts are given by:

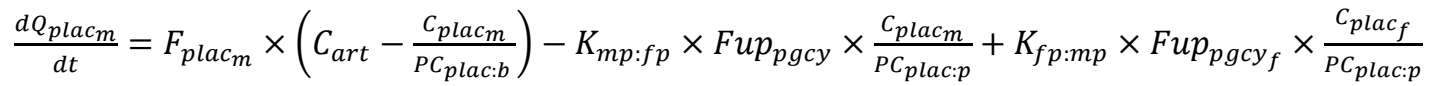

$$
\begin{aligned}
& \frac{d Q_{\text {plac }_{f}}}{d t}=F_{\text {plac }_{f}} \times\left(C_{\text {art }_{f}}-\frac{C_{\text {plac }_{f}}}{P C_{\text {plac }: b}}\right)+K_{m p: f p} \times F u p_{\text {pgcy }} \times \frac{C_{\text {plac }_{m}}}{P C_{\text {plac }: p}}-K_{f p: m p} \times F u p_{\text {pgcy }_{f}} \times \frac{C_{\text {plac }_{f}}}{P C_{\text {plac }: p}}
\end{aligned}
$$

with $C_{\text {plac }}$ the placenta concentration in the perfusion model $(\mathrm{mg} / \mathrm{L}), C_{\text {placm }}$ the maternal placenta concentrations $(\mathrm{mg} / \mathrm{L}), C_{\text {placf }}$ the fetal placenta concentration $(\mathrm{mg} / \mathrm{L}), F_{\text {placm }}$ the blood flow of the maternal placenta compartment (L/min), $F_{\text {placf }}$ the blood flow entering the fetal placental compartment (L/min), $P C_{p l a c: b}$ the placenta:blood partition coefficient, $K_{m p: f p}$ and $K_{f p: m p}$ the diffusional placental transfer constants from the mother to the fetus and vice-versa (L/min), Fup $p_{p g c y}$ and Fup $p_{p c y f}$ the free plasma fractions in the mother and the fetus, respectively. The latter is presented in the Model parameterization section. Due to different plasma protein concentrations during pregnancy in the mother and the fetus, Fup $p_{p g c y}$ and Fuppgcyf $v a l u e s$ were different and hence the mother to fetus and fetus to mother placental transfer rates were automatically asymmetrical.

\section{Model parameterization}


In this section, we present the maternal and fetal physiological parameterization according to the published data and the placental transfer parameterization. Compound-specific parameters will be given in the Model evaluation section below. Time-dependent physiological equations can be expressed according to either fertilization age ( $F W$ in weeks) or gestational age ( $G W$ in weeks). $F W$ denotes the elapsed time since the ovum fertilization whereas $G W$ considers the time since the first day of the last menstrual period that precedes conception. Ovum fertilization occurs, on average, 14.6 days after the last menstrual period.

\section{Physiological parameters}

Fertilization (or gestational) age-dependent equations were implemented in the pPBPK model for the maternal physiological parameters (tissue volumes and blood flows) mainly using the metaanalysis performed by Dallmann, Ince, Meyer, et al. (2017). Table S1 and Table S2 in Supplemental Material present the equations of the tissue volumes and blood flows, respectively. The maternal bodyweight was computed as the sum of the initial bodyweight with the gestational weight gain. The tissue volumes (gut, kidneys, liver and lungs) and blood flows (gut and liver) which do not change during pregnancy were expressed as a fraction of initial bodyweight or the cardiac output, respectively. The volume of the rest of body compartment was assumed to remain stable during pregnancy and was computed at the start of pregnancy by subtracting the sum of all tissue volumes to the initial bodyweight. The blood flow to the rest of body compartment was computed by subtracting the sum of all tissues blood flows to the cardiac output.The fetal bodyweight $\left(B W_{f}\right)$ was computed as presented in Luecke et al. (1994), as well as the compartments' growth (Table S3 in Supplemental Material). provides the parameterization of the $\alpha$ and $\beta$ allometric parameters. The fetal plasma cardiac output, taken from Luecke et al. (1994), was turned to fetal blood cardiac output with fetal hematocrit. The umbilical vein blood flow $\left(F_{\text {placf }}\right)$ was assumed to start at $\mathrm{GW}=3.6$ weeks, when the uteroplacental circulation is established (Kapraun et al. 2019). Several equations were tested in the model (Dallmann, Ince, Meyer, et al. 2017; Zhang et al. 2017; Kapraun et al. 2019), but for the five first $F W$, either the computed $F_{\text {placf }}$ were above the fetal blood cardiac output or presented negative values. $F_{\text {placf }}$ was then assumed to be proportional to the placenta volume during pregnancy with the 
value at the end of pregnancy set to the value obtained by Dallmann, Ince, Meyer, et al. (2017). Furthermore, the blood flows through the ductus venosus and the portal sinus were set as constant fractions of $F_{\text {placf. }}$ All the fetal blood flows equations are given in Supplemental Material.

The pPBPK model also includes the changes in maternal and fetal hematocrit, albumin and $\alpha-1$ glycoprotein serum concentrations and the increase in maternal $F_{G F R}$ during pregnancy. Maternal parameters equations were taken from Dallmann, Ince, Meyer, et al. (2017), and fetal parameters equations from Zhang et al. (2017), except for albumin fetal serum concentration equation which was determined by linear regression on Krauer et al. (1984) data. For each compound, both maternal $\left(F_{p u p_{p c y}}\right)$ and fetal $\left(F_{p u p} p_{p c y f}\right)$ plasmatic free fractions were computed according to their estimated affinity to plasmatic proteins (from non-pregnant women values assuming that the number of binding sites and the affinity remain constant) and the evolving concentration of the latter during pregnancy. The plasmatic protein concentration equations are given in Supplemental Material for the mother and the fetus.

\section{Placental transfers}

Four placental transfer models were defined: the blood perfusion-limited $(P L)$ model and the diffusion-limited model parameterized by three approaches. These approaches are based on in silico $(S E)$, in vitro $(\operatorname{InV})$ or ex vivo $(E x V)$ data to parameterize the passage of the compounds from the mother to the fetus and vice-versa $\left(K_{m p: f p}\right.$ and $\left.K_{f p: m p}\right)$. All the transfer constants varied during pregnancy according to the changes in the placental blood flows, the thickness and the surface of the membrane of exchange, or the volume of the placenta.

\section{Diffusion-limited structure: SE model}

This approach was proposed by Dallmann, Ince, Solodenko, et al. (2017). It assumes that the diffusion of a substance through the placenta is driven by two physicochemical parameters: the logarithm of the membrane affinity $(\log M A)$ and the efficient molecular weight (i.e., considering the presence of halogen atoms in the molecule, $M W_{\text {eff }}$. The authors defined a semi-empirical equation that 
predicts the intrinsic permeability of the membrane $\left(P_{\text {int }}\right.$ in $\left.\mathrm{dm} / \mathrm{min}\right)$ separating maternal and placental blood as follows:

$P_{i n t}=\left(\frac{M W e f f}{336}\right)^{-6} \times \frac{10^{\log M A}}{5} \times 10^{-7}$

The permeability surface area product $K_{m p: f p}$ is then obtained from $P_{i n t}$ by adjustment to the placenta physiology, i.e. the syncytiotrophoblast membrane surface $\left(\operatorname{Surf}_{\text {sct }}\right.$ in $\left.\mathrm{dm}^{2}\right)$ and thickness $\left(T h_{s c t}\right.$ in $\left.\mathrm{dm}\right)$ as follows:

$K_{m p: f p}=P_{\text {int }} \times \operatorname{Surf}_{\text {sct }} \times \frac{T h_{\text {sct }}}{T h_{\text {sct }} \text { ref }}$

with $P_{\text {int }}$ the intrinsic membrane permeability expressed in $\mathrm{dm} / \mathrm{min}$. Here, we assumed that it corresponded to the membrane permeability at the reference thickness value ( $T h_{\text {sctref }}$ expressed in $\left.\mathrm{dm}\right)$. The latter was estimated from the $A U C$ of the $T h_{s c t}$ equation, which is presented in Supplemental Material, as well as the $\operatorname{Surf}_{s c t}$ equation. Finally, in this approach, $K_{m p: f p}$ and $K_{f p: m p}$ have similar values.

\section{Diffusion-limited structure: InV model}

This approach was adapted from Zhang and Unadkat (2017) and consists in estimating the intrinsic permeability $\left(P_{\text {int }}\right)$ from an in vitro apparent permeability (Papp) by adjusting this latter to the in vitro apparent permeability of a reference compound (here midazolam):

$P_{\text {int }}=\frac{\text { Papp }}{\operatorname{Papp}_{M D Z}} \times P_{\text {int }, M D Z}$

with $P_{i n t, M D Z}$ stands for midazolam intrinsic permeability computed from Zhang and Unadkat (2017) as follows:

$P_{\text {int }, M D Z}=\frac{C L P D_{u, M D Z} \times F u_{p g c y_{M D Z, t e r m}}}{\operatorname{Surf}_{\text {sct }, \text { term }}}$

where $\operatorname{Surf}_{\text {sct,term }}, C L P D_{u, M D Z}$ and Fup $p_{p g c y M D Z, \text { term }}$ are the syncytiotrophoblast surface, the unbound passive in vivo diffusion clearance estimated by Zhang and Unadkat (2017) and the plasmatic free fraction of midazolam, at term, respectively. The $P_{\text {int }}$ was then scaled to in vivo transfer constant as done for the $S E$ model (Eq.11). Here, $K_{m p: f p}$ and $K_{f p: m p}$ present similar values. 


\section{Diffusion-limited structure: ExV model}

This approach was adapted from Schalkwijk et al. (2018) and De Sousa Mendes et al. (2016) that estimated the placental transfers at term using ex vivo placenta perfusion studies. The experiments consist in the perfusion of a placental cotyledon at the interface of a maternal-like and a fetal-like reservoirs and in monitoring the transfers of compounds from the maternal reservoir to the fetal one and vice-versa. The first-order constants were then used to compute a cotyledon passive diffusion parameter $\left(D_{c o t}\right.$, in $\left.\mathrm{L} / \mathrm{min}\right)$ :

$D_{c o t} t_{m p f p}=k_{d_{m p: f p}} \times V_{M R}$

$D_{c o t}^{f p: m p}=k_{d_{f p: m p}} \times V_{F R}$

where $V_{M R}$ and $V_{F R}$ are the maternal and fetal reservoirs volumes in L, respectively. These transfer constants were then scaled to the whole placenta as follows:

$K_{m p: f p}=D_{c o t} t_{m p: p} \times \frac{V_{p l a c}}{V_{c o t}}$

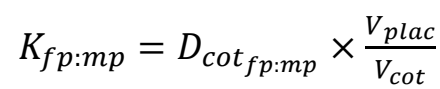

where $D_{\text {cotmp:fp }}, D_{\text {cotfp:mp }}$, represent maternal to fetal reservoirs and fetal to maternal reservoirs cotyledon passive diffusion constants expressed in $\mathrm{L} / \mathrm{min} . V_{\text {plac }}$ and $V_{\text {cot }}$ stand for the placental and one cotyledon volumes both expressed in L, respectively. In this approach, $K_{m p: f p}$ and $K_{f p: m p}$ can have different values.

\section{Model evaluation}

\section{Compounds}

We selected drug monitoring studies which provide pharmacokinetic fetal data for a short period of time after a controlled administration to the mother (Table 1). Most of the maternal and fetal data were collected at the end of pregnancy. Data for ten therapeutic drugs were collected: midazolam (MDZ), theophylline (THEO), zidovudine (ZIDO), nevirapine (NEVI), lamivudine (LAMI), emtricitabine (EMTRI), cefuroxime (CEFU), diazepam (DZP), ondansetron (OND) and metronidazole (MNZ). All these compounds have a short elimination half-life, i.e. the complete elimination from the maternal 
body is between hours to days. For NEVI, LAMI and EMTRI, the observed maternal concentrations cannot be properly discriminated from the published figures but most of them were collected to be compared to the pPBPK model predictions. CEFU, DZP, OND and MNZ maternal data were downloaded from PK-Sim ${ }^{\circledR}$. For four substances (ZIDO, OND, CEFU and MNZ), maternal and fetal concentrations in early pregnancy were identified in the literature. ZIDO and OND first trimester data were given as fetal to maternal concentration ratios at a specific time point (S.-S. N. Siu, Chan, and Lau 2006; S.-S. Siu et al. 2005). No information was given in the original publications regarding the sampling times in fetuses. The maternal times were set so that the model predictions fitted the maternal measured concentrations and the fetal sampling time was assumed to occur 15 minutes later to account for the surgical procedure.

The compound-specific parameters of the pPBPK model (absorption first-order constant kgutabs; bioavailability $F$; initial plasma fraction unbound $f u$; and the ratio blood to plasma $R b p$ ) were informed with published values from previous models (Table 2). The tissue:blood partition coefficient $\left(P C_{t: b}\right)$ were calculated from in silico estimated tissue to plasma partition coefficients $\left(P C_{t: p}\right)$ corrected by the blood-to-plasma ratio. For all compounds but one, the in silico tools implemented in PK-Sim ${ }^{\circledR}$ were used to predict $P C_{t: p}$. For ZIDO, the Schmitt's function integrated in the httk package was used (Schmitt 2008). When the in silico method predicted the unbound tissue:plasma partition coefficients $\left(P C_{u, t: p}\right)$ instead of $P C_{t: p}$, it was corrected with the plasma free fraction $(f u)$. Finally, for all compounds the fetal $P C_{t: b}$ were assumed equal to the maternal ones. All the $P C_{t: p}$ are presented in Supplemental Material (Table S4, S5 and S6). The non-pregnant elimination clearances $\left(C L_{m e t}, C L_{r}\right.$ and $\left.C L_{s y s}\right)$ were calculated by different approaches according to the type of available information (see Table 2). To account for the variations of the metabolic clearance through pregnancy, the values of the metabolic fraction per enzymes are reported in Supplemental Material (Table S7).

Table 3 presents the values of the placental exchange parameters that have been used in each transfer model. The parameter $\log M A$ was computed with a regression equation used in httk (Yun, Cotton, and Edginton 2014) which was derived from the Schmitt's dataset (Schmitt 2008). The $M W_{\text {eff }}$ values were estimated using the equations derived by Willmann et al. (2003) implemented in PK- 
Sim $^{\circledR}$. The permeability Papp values were taken from the literature considering only those obtained from epithelial cell lines with tight junctions between cells in monolayer cultures (i.e., MDCK and Caco-2). To avoid cofounding bias, we selected studies for which the experiments have been conducted in the absence of binding proteins, except for LAMI whose Papp was corrected by fu. When multiple data were available for a substance, the mean Papp value was calculated (Table 3). No Papp data were found for EMTRI. Concerning the ExV model parameterization, the cotyledon firstorder constants $k_{d m p: f p}$ and $k_{d f p: m p}\left(\right.$ in $\min ^{-1}$ ) were estimated by a non-compartmental analysis from the slope of the natural log concentration time profiles of the maternal and fetal reservoirs, respectively. Among the ex vivo experimental studies, the perfusion medium used was protein-free only for DZP (Myllynen and Vähäkangas 2002).

\section{Variability and sensitivity analyses}

We performed Monte Carlo (MC) simulations $(\mathrm{n}=10,000)$ in order to assess the impact of interindividual variability and uncertainty in parameters' values of the pPBPK model on the maternal and fetal concentrations. We assigned truncated normal distributions to the physiological and compoundspecific parameters (absorption, elimination, partition coefficients, placental transfer parameters) with a variation coefficient of $30 \%$ and $50 \%$, respectively.

A global variance-based sensitivity analysis (SA) was conducted on the pPBPK model to identify the compound-specific parameters which had the most impact on the internal fetal exposure. We selected two model outputs: the maximal fetal plasma concentrations $\left(\operatorname{Cmax}_{f e t}\right)$ and the area under the fetal plasma concentration-time curve $\left(A U C_{f e t}\right)$. The Sobol method was used for the analysis (Sobol' et al. 2007). The analysis was run for a theoretical substance that is eliminated by hepatic metabolism only and fully absorbed. For most of the parameters, truncated normal distributions were assigned with a coefficient of variation of $100 \%$ or $50 \%$ around their mean value. A lognormal distribution and a log-uniform distribution were assigned to the hepatic clearance and the placental transfers, respectively, to allow very low values (Table S8 in Supplementary Material). The SA was run at the end of each trimester of pregnancy ( $F W=13,26$ and 39 weeks). Model output variances were estimated employing MC integrals from two independent input samples $n_{1} \times p_{1}$ matrices (the "sample" 
matrix M1 and the "resample" matrix M2), with $\mathrm{n}_{1}$ the sample size $\left(\mathrm{n}_{1}=100,000\right)$ and $\mathrm{p}_{1}$ the number of parameters. Each row in M1 and M2 stands for a possible parameter combination. SA results are presented as two indices: the first order index (FOI) which is the variance contribution of one parameter to the total model variance, and the total order index (TOI) which is the result of the main effect of the parameter and of its interactions with the other parameters.

\section{Software}

The pPBPK model was built in GNU MCSim (Bois 2009) software (available at http://www.gnu.org/software/mcsim/). It converts model equations into $\mathrm{C}$ code and solves it by numerical integration. The R software was used for graphics (R Core Team 2018).

\section{RESULTS}

\section{Model evaluation: non-pregnant profiles}

Before proceeding to the pPBPK model evaluation, we first assessed the predictions for nonpregnant women in order to ensure that our evaluations focused on pregnancy will not be biased by a poor predictive performance of the non-pregnant period. In that respect, plasma concentrations were simulated for non-pregnant women and compared to observed in vivo data for the ten selected compounds. The non-pregnant model corresponds to the pPBPK model parameterized with the initial values for volumes and blood flows. The posology and subjects' information are given in Supplemental Material (Table S9). The predicted pharmacokinetic profiles adequately described the observed plasma concentrations for all the substances but NEVI and EMTRI. We then reparameterized the bioavailability for NEVI and the absorption rate constant for EMTRI by visual fitting to improve the model predictability. Although the absorption and elimination slopes in the initial NEVI profile seemed correct, the concentrations were constantly over-predicted. Concerning EMTRI, both the initial absorption and elimination slopes seemed steeper than the observed ones. The initial profiles are provided together with the updated profiles in Supplemental Material (Figure S2 \& S3). The adjusted values were used in the following and are given in Table 2. After the calibration of these two parameters, more than $80 \%$ of the simulated concentrations were within the two-fold error 
interval, except for LAMI (67\%) and MNZ (76\%). The model predictability could be a bit lower for the times far from the administration at low concentrations (e.g., LAMI).

\section{Model evaluation at term}

The pPBPK model including the placental transfers models was evaluated in maternal plasma at term for the ten selected compounds (Figure 2). Globally, the simulated profiles well described the data. The impact of the placental transfer modelling on the simulated maternal concentration-time profiles was limited since the four profiles showed similar results. For instance, the maximal deviation between the four models for MDZ was less than $6 \%$. The only significant difference was for LAMI at the end of the elimination phase at low concentrations (Figure S4 in Supplemental Material). Table 4 presents the predicted maximum maternal plasma concentration (Cmax) and time to reach Cmax (Tmax) for orally administered compounds, but only for the perfusion-limited transfer since model predictions were similar for the four placental transfer models. Because the data covered the whole pharmacokinetic phase for each compound, the observed Cmax and Tmax were identifiable even if the sampling times for NEVI, EMTRI and LAMI were highly variable between the individuals. The predicted Cmax and Tmax were all within a two-fold error range except Tmax for LAMI (the relative error was equal to $-73.2 \%$ ). Therefore, the pPBPK model presents a good accuracy in maternal Cmax and Tmax predictions at term.

The sampling times of the fetal data for model evaluation were heterogeneous due to the alea in the time of delivery. For few substances, the observed data were not available in the elimination phase (MDZ, NEVI and MNZ). Inversely, data in the early pharmacokinetic phase were lacking for OND and CEFU. Such shortcomings rendered the assessment not fully complete. The predictive performance of the four placental transfer models was assessed by comparing their predictions to measured umbilical cord plasma concentrations at term (Figure 3 for the pharmacokinetic profiles, Figure 4 for the goodness-of-fit plots based on measured umbilical cord concentrations, and Figure S6 for the goodness-of-fit plots based on plasma $\left.C \max _{f e t}\right)$. As expected, the placental transfer models had 
an influence on the simulated profiles (Figure 3). The fetal profiles simulated with the $P L$ model followed the maternal profiles and had systematically the highest fetal intake rate with the ability to reach $C_{\text {maxfet }}$ faster than the other models. For several substances, the $P L$ and $I n V$ profiles were quite close (overall profile for THEO, NEVI and MNZ, or their elimination slopes for OND and DZP), but for other substances the $\operatorname{In} V$ profiles exhibited a diffusion-limited distribution in the fetus. In most of the cases, the $S E$ and $E x V$ profiles were well below the $P L$ and $\operatorname{In} V$ ones and were seemed extremely flat for six substances (MDZ, ZIDO, CEFU, MNZ, DZP and OND). Regarding the substances tested, several types of fetal pharmacokinetics can be generated by the four transfer models.

The $P L$ model showed a slight tendency to overprediction, whereas the $S E$ model showed a tendency to underprediction. No such pattern was observed for the $\operatorname{In} V$ and $\operatorname{ExV}$ models. For all compounds but OND, at least one of the simulated profiles was in good agreement with the observed data. However, the model with the best predictability often differed between substances: the $P L$ model showed the best performance for 6 of the 10 substances (MDZ, THEO, ZIDO, DZP, MNZ, CEFU); the $S E$ model for three substances (NEVI, EMTRI and LAMI); the InV model for two substances in association with the PL model (THEO and MNZ) and also for LAMI in association with $S E$ model; the $E x V$ model was never the best fit but was evaluated on four substances only.

The In $V$ model showed the highest percentage (81\%) of predictions within the three-fold interval followed by the $S E$ (71\%), PL (67\%) and $E x V$ models (41\%), and the lowest percentage of predictions out of the ten-fold error interval (6\%), followed by the $S E$ (11\%), PL (16\%) and ExV (18\%) models (Table S10 in Supplemental Material). These results were highly dependent on the number of data per substance. If a model performs well for a compound with numerous data, the predictive performance will be high. The reverse is also true: a poor performance for a compound with numerous data will decrease predictability. For instance, the $S E$ model presented its highest predictive performance for three compounds which had the highest number of data (NEVI, EMTRI and LAMI). We then computed the number of times a transfer model showed the best predictability per substance and presented the results as relative percentages $(\%=$ number of times a model shows the best performance / number of substances tested with this model). Concerning the $\operatorname{In} V$ model ( 9 tested 
substances), $78 \%$ of the tested substances had at least $80 \%$ of their simulated concentrations within the three-fold error interval. In comparison, the predictive performance of the $P L, S E$ and $E x V$ models were much lower with respectively $50 \%, 40 \%$ and $25 \%$ of their tested substances which met the similar criteria. The ExV model showed the highest percentage of simulated concentrations out of the ten-fold error interval for 50\% (i.e., EMTRI 17\% and DZP 81\%) of the tested substances. The SE, PL and $\operatorname{InV}$ models followed in decreasing order with $40 \%, 20 \%$ and $11 \%$, respectively. Finally, the same ranking of the models was obtained from the four criteria presented here starting from the best performances: $I n V, P L, S E$ and $E x V$ models. In only one case, the $S E$ model performed better than the $P L$ model.

Table 5 compares the simulated and observed plasma $C \max _{\text {fet }}$ and $T_{\operatorname{maxfet}}$ for the four placental transfer models. Concerning the simulated maximum concentrations, $70 \%$ of $\mathrm{Cmax}_{f e t}$ simulated with the $S E$ model were within the ten-fold error range and $50 \%$ within the three-fold error interval. All the $\mathrm{Cmax}_{f e t}$ simulated with the InV model were within the ten-fold error range and $67 \%$ were within the three-fold error interval. The $\operatorname{Cmax}_{f e t}$ simulated with the $P L$ model were all comprised within the three-fold error range and it must also be noticed that $60 \%$ of corresponding $T_{\text {maxfet }}$ were within the [$50-100 \%$ ] relative error interval. Furthermore, the uncertainty intervals simulated by the $P L$ model were narrower than the ones of the other models and were included within the ten-fold error range, except for EMTRI. Finally, $75 \%$ of $\operatorname{Cmax}_{\text {fet }}$ simulated with the $E x V$ model were within the ten-fold error range and 50\% within the three-fold error range.

\section{Model evaluation: early pregnancy}

The pPBPK model was also evaluated in early pregnancy for MNZ, ZIDO and OND, and at the start of the third trimester for CEFU for the $S E, \operatorname{In} V$ and $P L$ models since no ex vivo data were available for the $E x V$ model calibration. Figure 5 presents the predictive performance for ZIDO and OND in early pregnancy in the form of boxplots of the simulated ratios of the fetal tissue concentrations over the maternal plasma concentrations (F/M). For all transfer models, the interquartile range (IQR) of the simulated ratios were wider than the observed ones. The ZIDO simulations with the SE model almost contained the observed IQR (simulated IQR: [0.52-2.02] and 
observed IQR: [0.40-1.36]) whereas the InV and $P L$ models overpredicted the ratios (simulated IQR:[0.96-1.96] for $I n V$, [0.91-1.80] for $P L)$. Concerning OND, the simulated IQR with the $S E$ model contained the data whereas the simulated IQR with the $P L$ and $\operatorname{In} V$ model were largely above the observed values. Finally, for both substances the $S E$ model's predictions presented the best agreement to the data. For MNZ, the simulated placental, fetal tissue and plasma pharmacokinetics well described the data (Figure S7 in Supplemental Material). The simulated pharmacokinetics were close for the three models. In each case, the observed data were contained within simulated 2.5th-97.5th percentile ranges of each model. In fetus and placenta, the $\operatorname{InV}$ and $P L$ predictions were similar, and the $S E$ model simulated high Tmax in comparison to the InV and $P L$ models. The uncertainty intervals were also wider with the $S E$ model.

For CEFU in early third trimester, the maternal predictions were similar for the three models and well described the data (Figure 6). Regarding the fetal toxicokinetics, the predictions of the three models differed. The $\operatorname{In} V$ and $S E$ models' simulations were rather constant and the $\operatorname{In} V$ predicted levels were above the $S E$ model ones. and their intervals of uncertainty practically never overlapped. The $P L$ model simulations showed the best agreement with the observed values and the highest level for $C_{\text {maxfet }}$ with the fastest $T_{\text {maxfet }}$ among the three models. The interval of uncertainty was the only one to contain all the observed data. For both the mother and the fetus, the predicted intervals were quite large, specially at low doses. The predicted uncertainty was driven by the distributions assigned to the model's parameters whose variations were close to the human inter-individual variability affecting the ADME processes (30\% or $50 \%$ of variation depending on the process). Refining the distributions of the most influential parameters (such as the clearances) should result in narrower intervals.

\section{Impact of the placental transfer models on the fetal dosimetry}

The impact of the placental transfer models on the fetal internal dosimetry was evaluated at the three different trimesters of pregnancy (at $F W=13,26$ and 39 weeks) with compounds for which all the placental transfer parametrization information was available (i.e., THEO, NEVI and DZP). Table 10 summarizes the values of the transfer constant $K_{m p: f p}$ (and $K_{f p: m p}$ for the $E x V$ model), of $C m a x_{f e t}$ and $A U C_{24 f e t}$ simulated by each transfer models. As expected, the simulated $K_{m p: f p}$ values increased as the 
term of pregnancy approaches. The ExV model simulated the lowest $K_{m p: f p}$ values for THEO and NEVI at each trimester. For all placental transfer models but $E x V$ model, the $A U C_{24 f e t}$ tends to increase throughout pregnancy. Mixed results were observed for $\operatorname{Cmax}_{\text {fet }}$ : it increases along pregnancy with the $P L$ model whereas it decreases with the $E x V$ model, and no general trends can be identified for the $S E$ and $\operatorname{In} V$ models except a small decrease during the second trimester.

The differences in $\operatorname{Cmax}_{f e t}$ and $A U C_{24 f e t}$ predictions by the placental transfer models changed as pregnancy progressed and among the three compounds, DZP exhibited the highest differences between the models. The mean relative error between the highest and the lowest simulated Cmax $x_{f e t}$ increased from $244 \%$ in $\mathrm{T} 1$ to $1486 \%$ in T3. A similar trend was found with the mean relative error between the highest and the lowest simulated $A U C_{24 f e t}$ values (28\% in T1; 581\% in T3). Therefore, the first trimester was the period for which the simulated fetal plasma peak and average internal exposures were the closest between the transfer models after a single maternal exposure. In general, the $A U C_{24 f e t}$ predicted by the InV and $P L$ models were quite close.

Figure 7 presents the simulated fetal plasma concentration-time profiles of THEO, NEVI and DZP at the end of the three trimesters of pregnancy. The $P L$ profiles only presented elimination phase slopes as the $\operatorname{Cmax}_{\text {fet }}$ were close to the initial time point. As observed in our other simulations, on one hand the $P L$ and $I n V$ profiles were similar (rapid intake and fast elimination), and on the other hand $S E$ and ExV models provided similar profiles but different from the $P L$ and $\operatorname{InV}$ models (longer absorption). For each substance, the second and third trimester profiles were close and could differ from the first trimester profile specially for the $S E$ and $E x V$ models. Indeed, in each case the first trimester profile showed higher initial but lower final plasma concentration levels than with the two other trimesters (except for DZP with the $E x V$ model). For all models but the $E x V$ one, the fetal exposure is the highest at the end of the third trimester. For the $E x V$, the period of highest exposure is the first trimester. In most cases, the shape of the pharmacokinetic profiles was rather similar between the trimesters and only their magnitudes differed.

\section{Sensitivity analysis}


The global sensitivity analyses identified the parameters to which the maximal concentration in the fetal plasma $\left(\operatorname{Cmax}_{f e t}\right)$ and the cumulative exposure in the fetal plasma, computed as the AUC $\left(A U C_{f e t}\right)$ are sensitive. As it could have been expected, the parameter driving the placental transfer $\left(K_{m p: f p}\right)$ was the most influential parameter towards fetal plasma exposure. Overall, the ranking of the parameters did not differ significantly through the three trimesters. Cmax $x_{f e t}$ was highly sensitive to three parameters: the placental transfers $\left(K_{m p: f p}\right)$, the metabolic clearance $\left(C L_{\text {metc }}\right)$ and the rest of body:plasma partition coefficient $\left(P C_{r: p}\right)$. To a lesser extent, the unbound fraction (fup) and the absorption rate $\left(k_{\text {gusabs }}\right)$ can impact $\operatorname{Cmax}_{f e t} . A U C_{f e t}$ was highly sensitive to the placental transfers $\left(k_{m p: f p}\right)$, the metabolic clearance $\left(C L_{m e t c}\right)$ and the unbound fraction $(f u p)$. After these parameters, three partition coefficients (adipose:plasma, placenta:plasma, and rest of the body:plasma) were identified. The rankings of the parameters by the first order and total order indices were similar and significant interactions were observed between the three most influential parameters (Figure S8 in the Supplemental Material).

\section{DISCUSSION}

In this study, we developed a new pPBPK model for characterizing maternal and fetal exposure through pregnancy, assessed its predictive capabilities associated to four placental transfer models and analyzed their impacts on fetal dosimetry throughout pregnancy. All our results were obtained for therapeutic substances with fast elimination kinetics due data availabilty.

The pPBPK model was able to adequately simulate the pharmacokinetics of the ten selected compounds in non-pregnant and pregnant women after oral, intravenous bolus or infusion intakes. For all compounds, the maternal model was parametrized using specific data or from previous PBPK models in order to provide adequate predictions of the maternal pharmacokinetics. Regardless of the placental transfer model included in the pPBPK model, the simulated maternal pharmacokinetic profiles were similar along the whole pregnancy. In other words, the placental transfers did not affect the pharmacokinetics in the mother. On the contrary, the fetal plasma pharmacokinetics varied highly in shape and magnitude according to the placental transfer model at different periods of pregnancy. Although general trends in the PK profiles can be identified according to the transfer model, it was not 
possible to identify a unique placental transfer model that showed undeniably the best predictive results for the set of tested substances. The models showing the highest estimated transfer values (i.e., the InV and $P L$ models) seemed better appropriate for predicting the fetal plasma concentration at term. Indeed, the $\operatorname{In} V$ model showed the highest agreement with the data and can generate a variety of different profiles. The fetal profiles simulated by the $P L$ model followed the maternal pharmacokinetics and were in all cases but one, the ones that predicted the highest fetal exposure. For some substances, the $P L$ profiles were not adequate and overpredicted the fetal exposure. The $S E$ and ExV models showed the lowest global performance and their profiles were generally flat a term, e.g. the ExV model showed the lowest placental transfer constants for nevirapine, theophylline and diazepam. For several compounds, their predictions underpredicted the actual pharmacokinetics. Regarding the model performance in early pregnancy, no general conclusions could be drawn as very few data were available. The $S E$ model provided accurate predictions compared to the $P L$ and $\operatorname{InV}$ models for the three tested substances but these results could be affected by the uncertainty about the sampling time in the fetus that was not reported in the original papers (S.-S. N. Siu, Chan, and Lau 2006; S.-S. Siu et al. 2005). We then assumed that the sampling occurred 15 minutes after the sampling time in the mother. Because the drug's distribution to the fetus was fast with the $P L$ and $\operatorname{InV}$ models, any deviations in the sampling time could impact drastically the predicted concentrations in fetus. In that respect, the predictions by the SE models are less subject to our assumption since the predicted profiles were flat.

Chronic toxicity in offspring can either result from an acute fetal exposure, even single, during a well-defined critical period within organogenesis as well as long-term exposure during the prenatal life (Fragki et al. 2017). Therefore, the fetal concentration peak $\left(\operatorname{Cmax}_{f e t}\right)$ and the cumulative exposure $\left(A U C_{f e t}\right)$ in plasma are both exposure metrics of particular interest. We assessed the impact of the four models on these exposure metrics. Both $\operatorname{Cmax}_{f e t}$ and $A U C_{24 f e t}$ were the closest between the transfer models within the first trimester. During that period, $A U C_{24 f e t}$ varied only by $28 \%$ between the lowest and the highest simulated values. Our results also showed similar rankings between the simulated $A U C_{24 f e t}$ and $\mathrm{Cmax}_{f e t}$ medians at every trimester (except for one substance in the first trimester). For all 
placental transfer models but $E x V$ model, the $A U C_{24 f e t}$ tends to increase throughout pregnancy. The growth in fetal plasma volume impacted the $A U C_{24 f e t}$ simulated with the $E x V$ model more than with the others, since in each model the simulated substance amount in the fetal plasma increased during pregnancy. The pPBPK model was also assessed for its predictability of $\operatorname{Cmax}_{f e t}$ at term. A higher confidence could be attributed to the $P L$ model predictions because its intervals were narrower than the ones of the other models. Unfortunately, the fetal data were usually too sparse to compute the observed $A U C_{f e t}$ limiting the assessment of the models.

In this study, we extended the recent works of Mian et al. (2020) and Liu et al. (2020) that performed a similar evaluation of three placental transfer models (all except the $P L$ model) on a reduced set of substances at the end of a full-term pregnancy (Mian et al. (2020) for acetaminophen and Liu et al. (2020) for emtricitabine and acyclovir). Like highlighted in our results, the authors also observed different trends among the three substances: for acetaminophen the shape of simulated fetal profiles were similar between the models whereas for emtricitabine and acyclovir the fetal profiles simulated with the semi-empirical model differed from the ones simulated with the ex vivo and in vitro models. Another common point is that the models showing the highest placental transfer constant in Liu et al. (2020) (i.e., ex vivo- and in vitro-based models) provided the most accurate predictions of fetal plasma concentrations. In our study, we also assessed our model for emtricitabine. The maternalto-fetal transfer constant estimated with ex vivo data $(17.5 \mathrm{~mL} / \mathrm{min})$ was close to the value used by Liu et al. (18.8 $\mathrm{mL} / \mathrm{min})$. However, the pharmacokinetic profiles were quite different as Liu et al. (2020) assumed a symmetrical transfer unlike in our study (i.e., fetal-to-maternal transfer constant was set to $1.6 \mathrm{~mL} / \mathrm{min}$ ). Therefore, our asymmetrical transfer assumption largely contributed to the accumulation of emtricitabine in the fetal plasma. The asymmetry of the transfers through the placenta was modelled for the $E x V$ model as mother-to-fetus and fetus-to-mother transfers were determined experimentally. Only four compounds were tested with various situations regarding the magnitudes of the transfers. In all cases, the asymmetry in the transfers associated with the ExV model did not exhibit a higher predictability compared to the three other models with symmetrical transfers. Nevertheless, this asymmetry could be plausible for two compounds that could be ionized at a physiological $\mathrm{pH}$. 
Theophylline is a weak base (one pKa equals to 8.6) and nevirapine is amphoteric (one pKa equals to 2.8). Because the fetal blood $\mathrm{pH}$ is lower in comparison to the maternal one, this could lead to the trapping of weak bases in the fetus and inversely weak acids in the mother (Heikkinen et al. 2017).

The placental transfer constant is not the only model parameter driving the plasma fetal exposure. For emtricitabine, the semi-empirical equation-based model in Liu et al. (2020) underpredicted the observed fetal data when our analogous model described well the observed data with a lower placental transfer constant estimated value $(2.5 \mathrm{~mL} / \mathrm{min})$. The sensitivity analyses help in identifying the model parameters that influence the fetal exposure, as done with our global sensitivity analysis and the local one performed by Mian et al. (2020). In our study, we showed that the fetal concentration were sensitive to the placental transfers together with some maternal parameters as the clearance and the fraction unbound, whereas Mian et al. (2020) identified the placenta:plasma partition coefficient as an influential parameter. Among the approaches tested here to parametrize the placental transfers, only the ex vivo cotyledon perfusion experiment is designed to inform on the partitioning into the placenta at term. Both sensitive analyses are complementary as the GSA helps in identifying the influential parameters over a wide range of compounds whose characteristics are specified by the distributions assigned to the model parameters whereas the local sensitive analysis focuses on a specific compound.

An additional critical point in selecting a placental transfer model is its ease of implementation, i.e. the parameters' calibration. The models tested here require various levels of information, from no specific data to dedicated experiments with fresh human tissues. The $P L$ model does not need to be calibrated for each substance since the placental transfers are limited by the blood flows. The $S E$ model only needs two physicochemical properties whose values are usually known: the molecular weight $(M W)$ and the $\log P$. Unlike those models, the $\operatorname{In} V$ and $E x V$ models require generating data on the chemical permeability. The first one needs dedicated monolayer cell experiments to measure the Papp whereas the ex vivo single-cotyledon perfusion experiment requires a fresh placenta. These two models are then more demanding in terms of resources than the $P L$ and $S E$ models (Aengenheister et al. 2018). 
The $S E$ and $\operatorname{In} V$ approaches are both based on a reference substance, i.e., the transfer of the new compound is computed based on the known transfer of the reference substance. If the equation used in the first method cannot be modified easily for another reference compound, the $\operatorname{In} V$ approach allows either to keep midazolam as the standard (Atoyebi et al. 2019) or to change for another compound (Strikwold et al. 2017). In that latter case, the transfer constant of the new reference compound must be calibrated using fetal cord blood data. In this work, we kept midazolam transfer as the reference value for the $\operatorname{In} V$ model and used the reference value of the transfer provided by Zhang and Unadkat (2017). Because that value could be impacted by the pPBPK model structure, it could be envisaged to update this reference value by adjusting our pPBPK model to the fetal concentration of midazolam. The use of another reference substance could be also considered in order to better match the physicoand biochemical properties of a chemical family of interest (e.g., hydrophilic compounds that passively diffuse with transfer rates much lower than placental blood flows, substrates of active transport enzymes expressed in the syncytiotrophoblast or persistent pollutants etc.).

Our study was based on publicly available data for the $S E, \operatorname{In} V$ and $E x V$ approaches. Quantitative structure/properties relationship publications have produced large databases of observed intestinal Papp from monolayer Caco-2 cell culture (Pham-The et al. 2013; Broccatelli et al. 2016) and of placental clearance index (or transfer index, fetal transfer ratio etc.) values from single-cotyledon perfused experiments (Hewitt et al. 2007; Giaginis et al. 2009). Those databases were mainly built for drug compounds and gathered studies from various laboratories which did not necessarily used harmonized experimental protocols. For instance, the maternal-like and fetal-like transport media composition can be variable (e.g., use of fetal bovine serum and lipids). In situation where proteins and lipids were added in transport media to account for binding, the physiologic differences observed between maternal and fetal blood content at term were not necessarily considered. This could impact the experimental transfers for highly bound compound. Furthermore, those physiological equilibrium are variable between stages of pregnancy. Although the Papp values are directly used in the InV approach, the ExV model does not include the ex vivo summary indexes but a cotyledon transfer constant estimated from the experimental concentrations collected in the maternal and fetal 
compartments. In this study, we identified only four substances (THEO, DZP, EMTRI and NEVI) which gathered the required level of information for estimating the cotyledon first-order constants and extrapolating them to the placenta.

The ex vivo experiment is designed to mimic the placental transfers in the third trimester of pregnancy or at term (Kovo and Golan 2008). Among the different models tested, the ExV one clearly identifies the period to which the transfer constant is estimated whereas the transfers estimated by the $S E$ and $\operatorname{In} V$ approaches do not correspond to any specific period of pregnancy. To date, no approach can represent the placental structure in the first trimester. The Caco-2 (and MDCK) cells brush-border structure are comparable to the microvilli structure at the surface of the mature chorionic villi (Crawley, Mooseker, and Tyska 2014). Although the transcellular diffusion of a substance through the monolayer of the intestinal cells with tight-junctions might be close to the one through the syncytiotrophoblast layer, efflux and influx active transporters expression at the apical or the basolateral faces would be different. A placental cell line would be more representative such as the primary trophoblast or the choriocarcinoma cells (BeWo, Jeg-3 and JAR cells) (F. Liu, Soares, and Audus 1997). The latter display biochemical and morphological characteristics reported for invasive trophoblast cells, but some functions remain altered since they are derived from placenta choriocarcinoma. Those cells readily form tight-junctioned monolayer when cultured on semipermeable membrane. Such in vitro experiments had not been conducted for our test substances but for other compounds. For instance, Strikwold et al. (2017) extrapolated placental transfer constants for a rat pPBPK model from Papp values estimated with a BeWo cell system for a series of phenolic compounds.

In every model, the rate of transfer was assumed to be maximal at the end of a full-term pregnancy. In the placental diffusion-limited models, the placental exchange constants were extrapolated to other periods of pregnancy according to the placental volume in the $E x V$ approach, and to the syncytiotrophoblast's surface and thickness in the two others. The evolution of the syncytiotrophoblast thickness was assumed to be directly proportional to the one of trophoblast cells throughout pregnancy. In the same way, the diffusion through the endothelium membrane in the stroma of fetal 
chorionic villus was assumed to be not limiting in chemical transfer (Aengenheister et al. 2018). However, extrapolation to other periods of pregnancy is challenging mainly because of the lack of information on the placental transporters. To date, placental active transport was only included in pPBPK models for manganese (Yoon et al. 2011) and for iodide/perchlorate (Lumen, Mattie, and Fisher 2013; Clewell et al. 2003; 2007; Sweeney et al. 2009). Besides qualitative understanding of human placental transporters ontogeny throughout pregnancy (Dallmann et al. 2019), quantitative expression/activity information are still limited (Anoshchenko et al. 2020). In each model but the SE model that describes per default only passive processes, the estimated transfer value was apparent since it implicitly combined active and passive passage processes. The deconvolution of those two would provide a better mechanistic understanding which would help in extrapolation to other periods of pregnancy but also to other compounds (Dallmann, Pfister, et al. 2018).

The pPBPK model presented in this work is based on the pre-existing PBTK adult model developed by US EPA and included in the R package httk (Pearce et al. 2017). US EPA has developed this in silico tool to address toxicokinetic modelling for chemicals undergoing high-throughput screening. We therefore chose to add a quite simple PBPK model for the fetus in order to be adapted to this framework, i.e. easy to use and parametrizable using in vitro or in silico data. Some simplifications about the fetal ADME processes were assumed mostly due to the lack of quantitative data. For instance, the placenta is assumed to be the only source of uptake and elimination for the fetus in our model. The model could be extended to account for the role of the liquid amniotic as several studies have shown the exchanges of compounds between the fetus and the amniotic liquid via dermal contact before the keratinization of the skin or via oral ingestion later in the pregnancy (Koutroulakis et al. 2014; Chappuy et al. 2004). Some pPBPK models already included a compartment representing the amniotic liquid (Loccisano et al. 2013; Verner et al. 2015; De Sousa Mendes et al. 2017; Schalkwijk et al. 2018). De Sousa Mendes et al. (2017) and Schalkwijk et al. (2018) assessed the impact of the amniotic fluid-fetal exchanges on the fetal dosimetry using sensitivity analyses for a pPBPK model and showed that these exchanges had little influence on simulated fetal concentrations. These results together with the interindividual variability and the uncertainty on the physiological 
parameters driving the exchanges between the fetus and the amniotic fluid, indicate that the modelling of such exchanges might be taken into account only in the case where specific experimental data support the role of the amniotic liquid in the pharmacokinetics of the compound of interest. Another extension of the model could be the modelling of the active transport in the placenta or the metabolism in the placenta and the fetus. The presence of transporter families in the placenta, such as ATP-binding cassette (ABC) and solute carrier (SLC), has been demonstrated at different times of pregnancy (Unadkat, Dahlin, and Vijay 2004; Walker et al. 2017). However, the paucity of quantitative data currently available prevents a direct use in a PBPK model (Anoshchenko et al. 2020). Regarding metabolism, several studies have shown the presence of phase I and phase II enzymes in the placenta and the fetus and the evolution of their abundance throughout the pregnancy (Syme, Paxton, and Keelan 2004; Saghir, Khan, and McCoy 2012; Bouazza et al. 2019). These two possible metabolic pathways are still rarely included in pPBPK models unless they significantly impact the fetal dosimetry. As an example, one can cite bisphenol A (BPA) whose glucuronide might contribute to the fetal exposure to bioactive BPA, following its deconjugation into parent BPA in fetal tissues or in placenta (Corbel et al. 2015; Sharma, Schuhmacher, and Kumar 2018). However, quantitative data specific to the placenta and fetus are rarely available, leading to extrapolate their metabolic activities from activities observed in adults (Sharma, Schuhmacher, and Kumar 2018).

Our pPBPK model belongs to non-animal alternative methods which could help in prioritization of compounds for quantitative risk assessment issues. For instance, the pPBPK could transpose in vitro toxicity doses into in vivo fetal internal doses (Louisse et al. 2010), refine associations found in epidemiological studies between exposure and health outcomes (Verner et al. 2013), or to compare the ranking of fetal dosimetry and their associated measured maternal levels from biomonitoring studies (Brochot et al. 2019). Applying our pPBPK model in biomonitoring or epidemiological studies may require some new developments to account for the nature of the biomarkers and of the exposure of the populations. Our pPBPK model does not includes the toxicokinetic or elimination of the metabolites. However, most of the non-persistent environmental pollutants (e.g., some plasticizers, pesticides etc.) are not directly monitored in the blood, but in urine as metabolites (Saravanabhavan and Murray 
2012). The coupling of a metabolite elimination compartment or a full pPBPK model for the metabolite(s) could be considered. Another extension could be the description of the dermal and the inhalation routes to account for aggregate exposures.

\section{CONCLUSION}

The current study reports the development and the assessment of a generic pPBPK model whose placental transfers are parameterized from non-animal methods based on in vitro, ex vivo, and in silico tools. Our model aims at predicting the fetal internal dose in target tissues throughout pregnancy. The four tested transfer models did not impact the maternal pharmacokinetics but provided different pharmacokinetic profiles in the fetus. None of the tested models showed the best predictive performance related to fetal exposure for the ten tested drugs. Two models ( $P L$ and $\operatorname{In} V$ ) exhibited a good performance, and the other two models a relatively poor performance on the tested substances at term. Regarding early pregnancy, the models calibrated with a slow distribution to the fetus better match the observations. The comparison of the profiles by the four models at the three trimesters of pregnancy provided mixed results and highlighted the differences between the placental transfer models. Finally, the four transfer models could be considered depending on the framework of the use of the pPBPK model and the availability of data or resources to inform their parametrization. Such modelling tool could help to better characterize the fetal exposure in prenatal exposome studies.

\section{ACKNOLEDGEMENTS}

We thank Frédéric Yves Bois and Enrico Mombelli for the discussions and useful comments on the methodology.

\section{FUNDINGS}

This work has received funding from the European Union's Horizon 2020 Research and Innovation program under Grant Agreement No 825712 (OBERON project). 


\section{REFERENCES}

Abduljalil, Khaled, Penny Furness, Trevor N. Johnson, Amin Rostami-Hodjegan, and Hora Soltani. 2012. "Anatomical, Physiological and Metabolic Changes with Gestational Age during Normal Pregnancy." Clinical Pharmacokinetics $51 \quad$ (6): 365-96. https://doi.org/10.2165/11597440-000000000-00000.

Aengenheister, Leonie, Kerda Keevend, Carina Muoth, René Schönenberger, Liliane Diener, Peter Wick, and Tina Buerki-Thurnherr. 2018. "An Advanced Human in Vitro Co-Culture Model for Translocation Studies across the Placental Barrier." Scientific Reports 8 (1): 5388-5388. https://doi.org/10.1038/s41598-018-23410-6.

Anoshchenko, Olena, Bhagwat Prasad, Naveen K. Neradugomma, Joanne Wang, Qingcheng Mao, and Jashvant D. Unadkat. 2020. "Gestational Age-Dependent Abundance of Human Placental Transporters as Determined by Quantitative Targeted Proteomics." Drug Metabolism and Disposition 48 (9): 735. https://doi.org/10.1124/dmd.120.000067.

Atoyebi, SA, RKR Rajoli, E Adejuyigbe, A Owen, O Bolaji, M Siccardi, and A Olagunju. 2019. "Using Mechanistic Physiologically-Based Pharmacokinetic Models to Assess Prenatal Drug Exposure: Thalidomide versus Efavirenz as Case Studies." European Journal of Pharmaceutical Sciences: Official Journal of the European Federation for Pharmaceutical Sciences 140: 105068. https://doi.org/doi:10.1016/j.ejps.2019.105068.

Beaudouin, Rémy, Sandrine Micallef, and Céline Brochot. 2010. "A Stochastic Whole-Body Physiologically Based Pharmacokinetic Model to Assess the Impact of Inter-Individual Variability on Tissue Dosimetry over the Human Lifespan." Regulatory Toxicology and Pharmacology 57 (1): 103-16. https://doi.org/10.1016/j.yrtph.2010.01.005.

Benaboud, Sihem, Didier K Ekouévi, Saik Urien, Elisabeth Rey, Elise Arrivé, Stéphane Blanche, Glenda Gray, et al. 2011. "Population Pharmacokinetics of Nevirapine in HIV-1-Infected Pregnant Women and Their Neonates." Antimicrobial Agents and Chemotherapy 55 (1): 33137. https://doi.org/10.1128/AAC.00631-10.

Benaboud, Sihem, Jean Marc Tréluyer, Saik Urien, Stéphane Blanche, Naim Bouazza, Hélène Chappuy, Elisabeth Rey, et al. 2012. "Pregnancy-Related Effects on Lamivudine Pharmacokinetics in a Population Study with 228 Women." Antimicrobial Agents and Chemotherapy 56 (2): 776. https://doi.org/10.1128/AAC.00370-11.

Bois, Frédéric Y. 2009. "GNU MCSim: Bayesian Statistical Inference for SBML-Coded Systems Biology Models." Bioinformatics $25 \quad$ (11): 1453-54. https://doi.org/10.1093/bioinformatics/btp162.

Bouazza, Naïm, Frantz Foissac, Déborah Hirt, Saïk Urien, Sihem Benaboud, and Gabrielle Lui and Jean-Marc Treluyer*. 2019. "Methodological Approaches to Evaluate Fetal Drug Exposure." Current Pharmaceutical Design 25 (5): 496-504. https://doi.org/10.2174/1381612825666190319102812.

Broccatelli, F., L. Salphati, E. Plise, J. Cheong, A. Gobbi, M.-L. Lee, and I. Aliagas. 2016. "Predicting Passive Permeability of Drug-like Molecules from Chemical Structure: Where Are We?" Molecular $\quad$ Pharmaceutics $13 \quad$ (12): https://doi.org/10.1021/acs.molpharmaceut.6b00836.

Brochot, Céline, Maribel Casas, Cyntia Manzano-Salgado, Florence A. Zeman, Thomas Schettgen, Martine Vrijheid, and Frédéric Y. Bois. 2019. "Prediction of Maternal and Foetal Exposures to Perfluoroalkyl Compounds in a Spanish Birth Cohort Using Toxicokinetic Modelling." Toxicology and Applied Pharmacology 379 (September): 114640. https://doi.org/10.1016/j.taap.2019.114640.

Chappuy, Hélène, Jean-Marc Tréluyer, Vincent Jullien, Jérôme Dimet, Elisabeth Rey, Maria Fouché, Ghislaine Firtion, Gérard Pons, and Laurent Mandelbrot. 2004. "Maternal-Fetal Transfer and Amniotic Fluid Accumulation of Nucleoside Analogue Reverse Transcriptase Inhibitors in Human Immunodeficiency Virus-Infected Pregnant Women.” Antimicrobial Agents and Chemotherapy 48 (11): 4332-36. https://doi.org/10.1128/AAC.48.11.4332-4336.2004.

Cherian, Philip T, Xiaoqian Wu, Lei Yang, Jerrod S Scarborough, Aman P Singh, Zahidul A Alam, Richard E Lee, and Julian G Hurdle. 2015. "Gastrointestinal Localization of Metronidazole by 
a Lactobacilli-Inspired Tetramic Acid Motif Improves Treatment Outcomes in the Hamster Model of Clostridium Difficile Infection.” The Journal of Antimicrobial Chemotherapy 70 (11): 3061-69. https://doi.org/10.1093/jac/dkv231.

Chevrier, Cécile, Gwendolina Limon, Christine Monfort, Florence Rouget, Ronan Garlantézec, Claire Petit, Gaël Durand, and Sylvaine Cordier. 2011. "Urinary Biomarkers of Prenatal Atrazine Exposure and Adverse Birth Outcomes in the PELAGIE Birth Cohort." Environmental Health Perspectives 119 (7): 1034-41. https://doi.org/10.1289/ehp.1002775.

Clayton-Smith, Jill, Rebecca Bromley, John Dean, Hubert Journel, Sylvie Odent, Amanda Wood, Janet Williams, et al. 2019. "Diagnosis and Management of Individuals with Fetal Valproate Spectrum Disorder; a Consensus Statement from the European Reference Network for Congenital Malformations and Intellectual Disability." Orphanet Journal of Rare Diseases 14 (1): 180-180. https://doi.org/10.1186/s13023-019-1064-y.

Clewell, Rebecca A., Elaine A. Merrill, Jeffery M. Gearhart, Peter J. Robinson, Teresa R. Sterner, David R. Mattie, and Harvey J. Clewell. 2007. "Perchlorate and Radioiodide Kinetics Across Life Stages in the Human: Using PBPK Models to Predict Dosimetry and Thyroid Inhibition and Sensitive Subpopulations Based on Developmental Stage." Journal of Toxicology and Environmental Health, Part A 70 (5): 408-28. https://doi.org/10.1080/15287390600755216.

Clewell, Rebecca A., Elaine A. Merrill, Kyung O. Yu, Deirdre A. Mahle, Teresa R. Sterner, David R. Mattie, Peter J. Robinson, Jeffrey W. Fisher, and Jeffery M. Gearhart. 2003. "Predicting Fetal Perchlorate Dose and Inhibition of Iodide Kinetics during Gestation: A Physiologically-Based Pharmacokinetic Analysis of Perchlorate and Iodide Kinetics in the Rat." Toxicological Sciences 73 (2): 235-55. https://doi.org/10.1093/toxsci/kfg081.

Codaccioni, Marc, Frédéric Bois, and Céline Brochot. 2019. "Placental Transfer of Xenobiotics in Pregnancy Physiologically-Based Pharmacokinetic Models: Structure and Data." $\begin{array}{lllll}\text { Computational } & \text { Toxicology } & 12 & \text { (November): } & 100111 .\end{array}$ https://doi.org/10.1016/j.comtox.2019.100111.

Corbel, Tanguy, Elisabeth Perdu, Véronique Gayrard, Sylvie Puel, Marlène Z. Lacroix, Catherine Viguié, Pierre-Louis Toutain, Daniel Zalko, and Nicole Picard-Hagen. 2015. "Conjugation and Deconjugation Reactions within the Fetoplacental Compartment in a Sheep Model: A Key Factor Determining Bisphenol A Fetal Exposure." Drug Metabolism and Disposition 43 (4): 467. https://doi.org/10.1124/dmd.114.061291.

Crawley, Scott W, Mark S Mooseker, and Matthew J Tyska. 2014. "Shaping the Intestinal Brush Border." The Journal of Cell Biology 207 (4): 441-51. https://doi.org/10.1083/jcb.201407015.

Dallmann, André, Ibrahim Ince, Katrin Coboeken, Thomas Eissing, and Georg Hempel. 2018. "A Physiologically Based Pharmacokinetic Model for Pregnant Women to Predict the Pharmacokinetics of Drugs Metabolized Via Several Enzymatic Pathways." Clinical Pharmacokinetics 57 (6): 749-68. https://doi.org/10.1007/s40262-017-0594-5.

Dallmann, André, Ibrahim Ince, Michaela Meyer, Stefan Willmann, Thomas Eissing, and Georg Hempel. 2017. "Gestation-Specific Changes in the Anatomy and Physiology of Healthy Pregnant Women: An Extended Repository of Model Parameters for Physiologically Based Pharmacokinetic Modeling in Pregnancy." Clinical Pharmacokinetics 56 (11): 1303-30. https://doi.org/10.1007/s40262-017-0539-z.

Dallmann, André, Ibrahim Ince, Juri Solodenko, Michaela Meyer, Stefan Willmann, Thomas Eissing, and Georg Hempel. 2017. "Physiologically Based Pharmacokinetic Modeling of Renally Cleared Drugs in Pregnant Women." Clinical Pharmacokinetics 56 (12): 1525-41. https://doi.org/10.1007/s40262-017-0538-0.

Dallmann, André, Xiaomei I. Liu, Gilbert J. Burckart, and John van den Anker. 2019. "Drug Transporters Expressed in the Human Placenta and Models for Studying Maternal-Fetal Drug Transfer." The Journal of Clinical Pharmacology 59 (S1): S70-81. https://doi.org/10.1002/jcph.1491.

Dallmann, André, Marc Pfister, John van den Anker, and Thomas Eissing. 2018. "Physiologically Based Pharmacokinetic Modeling in Pregnancy: A Systematic Review of Published Models." Clinical Pharmacology \& Therapeutics 104 (6): 1110-24. https://doi.org/10.1002/cpt.1084.

De Leeuw, Jan W., Frans J. M. E. Roumen, Peter X. J. M. Bouckaert, Harry M. H. G. Cremers, and Tom B. Vree. 1993. "Achievement of Therapeutic Concentrations of Cefuroxime in Early 
Preterm Gestations With Premature Rupture of the Membranes." Obstetrics \& Gynecology 81 (2): 255-60.

De Sousa Mendes, Maïlys, Deborah Hirt, Saik Urien, Elodie Valade, Naïm Bouazza, Frantz Foissac, Stephane Blanche, Jean-Marc Treluyer, and Sihem Benaboud. 2015. "Physiologically-Based Pharmacokinetic Modeling of Renally Excreted Antiretroviral Drugs in Pregnant Women." British Journal of Clinical Pharmacology 80 (5): 1031-41. https://doi.org/10.1111/bcp.12685.

De Sousa Mendes, Maïlys, Deborah Hirt, Cécile Vinot, Elodie Valade, Gabrielle Lui, Claire Pressiat, Naïm Bouazza, et al. 2016. "Prediction of Human Fetal Pharmacokinetics Using Ex Vivo Human Placenta Perfusion Studies and Physiologically Based Models." British Journal of Clinical Pharmacology 81 (4): 646-57. https://doi.org/10.1111/bcp.12815.

De Sousa Mendes, Maïlys, Gabrielle Lui, Yi Zheng, Claire Pressiat, Deborah Hirt, Elodie Valade, Naïm Bouazza, et al. 2017. "A Physiologically-Based Pharmacokinetic Model to Predict Human Fetal Exposure for a Drug Metabolized by Several CYP450 Pathways." Clinical Pharmacokinetics 56 (5): 537-50. https://doi.org/10.1007/s40262-016-0457-5.

Elkomy, M. H., P. Sultan, B. Carvalho, G. Peltz, M. Wu, C. Clavijo, J. L. Galinkin, and D. R. Drover. 2015. "Ondansetron Pharmacokinetics in Pregnant Women and Neonates: Towards a New Treatment for Neonatal Abstinence Syndrome." Clinical Pharmacology and Therapeutics 97 (2): 167-76. https://doi.org/10.1002/cpt.5.

European Environment Agency. 2019. Air Quality in Europe. https://www.eea.europa.eu//publications/air-quality-in-europe-2019.

Fragki, Styliani, Aldert H. Piersma, Emiel Rorije, and Marco J. Zeilmaker. 2017. "In Vitro to in Vivo Extrapolation of Effective Dosimetry in Developmental Toxicity Testing: Application of a Generic PBK Modelling Approach.” Toxicology and Applied Pharmacology 332 (October): 109-20. https://doi.org/10.1016/j.taap.2017.07.021.

Garberg, P., M. Ball, N. Borg, R. Cecchelli, L. Fenart, R.D. Hurst, T. Lindmark, et al. 2005. "In Vitro Models for the Blood-Brain Barrier." Toxicology in Vitro 19 (3): 299-334. https://doi.org/10.1016/j.tiv.2004.06.011.

Giaginis, Costas, Athina Zira, Stamatios Theocharis, and Anna Tsantili-Kakoulidou. 2009. "Application of Quantitative Structure-Activity Relationships for Modeling Drug and Chemical Transport across the Human Placenta Barrier: A Multivariate Data Analysis Approach." Journal of Applied Toxicology 29 (8): 724-33. https://doi.org/10.1002/jat.1466.

Haugen, A C, T T Schug, G Collman, and J J Heindel. 2015. "Evolution of DOHaD: The Impact of Environmental Health Sciences." Journal of Developmental Origins of Health and Disease 6 (2): 55-64. https://doi.org/10.1017/S2040174414000580.

Heikkinen, Emma M., Hannu Kokki, Aki Heikkinen, Veli-Pekka Ranta, Juha Räsänen, Hanna-Marja Voipio, and Merja Kokki. 2017. "Foetal Fentanyl Exposure and Ion Trapping after Intravenous and Transdermal Administration to the Ewe." Basic \& Clinical Pharmacology \& Toxicology 120 (2): 195-98. https://doi.org/10.1111/bcpt.12665.

Hewitt, M., J. C. Madden, P. H. Rowe, and M. T. D. Cronin. 2007. "Structure-Based Modelling in Reproductive Toxicology: (Q)SARs for the Placental Barrier." SAR and QSAR in Environmental Research 18 (1-2): 57-76. https://doi.org/10.1080/10629360601053893.

Hirt, Déborah, Saik Urien, Elisabeth Rey, Elise Arrivé, Didier Ekouévi, Patrick Coffié, Sim Kruy Leang, et al. 2009. "Population Pharmacokinetics of Emtricitabine in Human Immunodeficiency Virus Type 1-Infected Pregnant Women and Their Neonates." Antimicrobial Agents and Chemotherapy 53 (3): 1067-73. https://doi.org/10.1128/AAC.00860-08.

Hsyu, Poe-Hirr, J. Frederick Pritchard, Haig P. Bozigian, Thomas L. Lloyd, Rita H. Griffin, Robert Shamburek, Gopal Krishna, and William H. Barr. 1994. "Comparison of the Pharmacokinetics of an Ondansetron Solution ( $8 \mathrm{Mg}$ ) When Administered Intravenously, Orally, to the Colon, and to the Rectum." Pharmaceutical Research 11 (1): 156-59. https://doi.org/10.1023/A:1018974501232.

Irvine, Jennifer D., Lori Takahashi, Karen Lockhart, Jonathan Cheong, John W. Tolan, H. E. Selick, and J. Russell Grove. 1999. "MDCK (Madin-Darby Canine Kidney) Cells: A Tool for Membrane Permeability Screening." Journal of Pharmaceutical Sciences 88 (1): 28-33. https://doi.org/10.1021/js9803205. 
Kanto, J, S Sjövall, R Erkkola, J-J Himberg, and L Kangas. 1983. "Placental Transfer and Maternal Midazolam Kinetics." Clinical Pharmacology \& Therapeutics 33 (6): 786-91. https://doi.org/10.1038/clpt.1983.107.

Kapraun, Dustin F., John F. Wambaugh, R. Woodrow Setzer, and Richard S. Judson. 2019. "Empirical Models for Anatomical and Physiological Changes in a Human Mother and Fetus During Pregnancy and Gestation." Plos One 14 (5): e0215906. https://doi.org/10.1101/438119.

Karhunen, M. 1984. "Placental Transfer of Metronidazole and Tinidazole in Early Human Pregnancy after a Single Infusion." British Journal of Clinical Pharmacology 18 (2): 254-57. https://doi.org/10.1111/j.1365-2125.1984.tb02465.x.

Koutroulakis, D., S. Sifakis, M.N. Tzatzarakis, A.K. Alegakis, E. Theodoropoulou, M.P. Kavvalakis, D. Kappou, and A.M. Tsatsakis. 2014. "Dialkyl Phosphates in Amniotic Fluid as a Biomarker of Fetal Exposure to Organophosphates in Crete, Greece; Association with Fetal Growth." Reproductive Toxicology 46 (July): 98-105. https://doi.org/10.1016/j.reprotox.2014.03.010.

Kovo, Michal, and Abraham Golan. 2008. "In Vitro Models Using the Human Placenta to Study Fetal Exposure to Drugs." Clinical Medicine. Reproductive Health 2 (January): CMRH.S974. https://doi.org/10.4137/CMRH.S974.

Krauer, Beatrice, P. Dayer, and R. Anner. 1984. "Changes in Serum Albumin and A1-Acid Glycoprotein Concentrations during Pregnancy: An Analysis of Fetal-Maternal Pairs." BJOG: An International Journal of Obstetrics \& Gynaecology 91 (9): 875-81. https://doi.org/10.1111/j.1471-0528.1984.tb03700.x.

Liu, Fei, Michael J. Soares, and Kenneth L. Audus. 1997. "Permeability Properties of Monolayers of the Human Trophoblast Cell Line BeWo." American Journal of Physiology-Cell Physiology 273 (5): C1596-1604. https://doi.org/10.1152/ajpcell.1997.273.5.C1596.

Liu, Xiaomei I., Jeremiah D. Momper, Natella Rakhmanina, John N. van den Anker, Dionna J. Green, Gilbert J. Burckart, Brookie M. Best, Mark Mirochnick, Edmund V. Capparelli, and André Dallmann. 2020. "Physiologically Based Pharmacokinetic Models to Predict Maternal Pharmacokinetics and Fetal Exposure to Emtricitabine and Acyclovir." The Journal of Clinical Pharmacology 60 (2): 240-55. https://doi.org/10.1002/jcph.1515.

Loccisano, Anne E, Matthew P Longnecker, Jerry L Campbell Jr, Melvin E Andersen, and Harvey J Clewell 3rd. 2013. "Development of PBPK Models for PFOA and PFOS for Human Pregnancy and Lactation Life Stages." Journal of Toxicology and Environmental Health. Part A 76 (1): 25-57. https://doi.org/10.1080/15287394.2012.722523.

Louisse, Jochem, Esther de Jong, Johannes J. M. van de Sandt, Bas J. Blaauboer, Ruud A. Woutersen, Aldert H. Piersma, Ivonne M. C. M. Rietjens, and Miriam Verwei. 2010. "The Use of In Vitro Toxicity Data and Physiologically Based Kinetic Modeling to Predict Dose-Response Curves for In Vivo Developmental Toxicity of Glycol Ethers in Rat and Man.” Toxicological Sciences 118 (2): 470-84. https://doi.org/10.1093/toxsci/kfq270.

Luecke, Richard H., Walter D. Wosilait, Bruce A. Pearce, and John F. Young. 1994. "A Physiologically Based Pharmacokinetic Computer Model for Human Pregnancy." Teratology 49 (2): 90-103. https://doi.org/10.1002/tera.1420490205.

Lumen, Annie, David R. Mattie, and Jeffrey W. Fisher. 2013. "Evaluation of Perturbations in Serum Thyroid Hormones During Human Pregnancy Due to Dietary Iodide and Perchlorate Exposure Using a Biologically Based Dose-Response Model.” Toxicological Sciences 133 (2): 320-41. https://doi.org/10.1093/toxsci/kft078.

Magnus, Per, Charlotte Birke, Kristine Vejrup, Anita Haugan, Elin Alsaker, Anne Kjersti Daltveit, Marte Handal, et al. 2016. "Cohort Profile Update: The Norwegian Mother and Child Cohort Study (MoBa)." International Journal of Epidemiology 45 (2): 382-88. https://doi.org/10.1093/ije/dyw029.

Maitre, Léa, Jeroen de Bont, Maribel Casas, Oliver Robinson, Gunn Marit Aasvang, Lydiane Agier, Sandra Andrušaitytè, et al. 2018. "Human Early Life Exposome (HELIX) Study: A European Population-Based Exposome Cohort." BMJ Open 8 (9): e021311-e021311. https://doi.org/10.1136/bmjopen-2017-021311.

Mandelli, M., P. L. Morselli, S. Nordio, G. Pardi, N. Principi, F. Sereni, and G. Tognoni. 1975. "Placental Transfer of Diazepam and Its Disposition in the Newborn." Clinical Pharmacology \& Therapeutics 17 (5): 564-72. https://doi.org/10.1002/cpt1975175564. 
Mian, Paola, Karel Allegaert, Sigrid Conings, Pieter Annaert, Dick Tibboel, Marc Pfister, Kristel van Calsteren, John N. van den Anker, and André Dallmann. 2020. "Integration of Placental Transfer in a Fetal-Maternal Physiologically Based Pharmacokinetic Model to Characterize Acetaminophen Exposure and Metabolic Clearance in the Fetus." Clinical Pharmacokinetics, February. https://doi.org/10.1007/s40262-020-00861-7.

Moore, R. G., and W. G. McBride. 1978. "The Disposition Kinetics of Diazepam in Pregnant Women at Parturition." European Journal of Clinical Pharmacology 13 (4): 275-84. https://doi.org/10.1007/BF00716363.

Myllynen, P., and K. Vähäkangas. 2002. "An Examination of Whether Human Placental Perfusion Allows Accurate Prediction of Placental Drug Transport: Studies with Diazepam." Journal of Pharmacological and Toxicological Methods 48 (3): 131-38. https://doi.org/10.1016/S10568719(03)00038-8.

Neuhaus, Winfried, Elisabeth Bogner, Michael Wirth, Joanna Trzeciak, Bodo Lachmann, Franz Gabor, and Christian R. Noe. 2006. "A Novel Tool to Characterize Paracellular Transport: The APTS-Dextran Ladder." Pharmaceutical Research 23 (7): 1491-1501. https://doi.org/10.1007/s1 1095-006-0256-z.

Omarini, D., M. M. Barzago, A. Bortolotti, G. Lucchini, F. Stellari, S. Efrati, and M. Bonati. 1993. "Placental Transfer of Theophylline in an in Vitro Closed Perfusion System of Human Placenta Isolated Lobule." European Journal of Drug Metabolism and Pharmacokinetics 18 (4): 369-74. https://doi.org/10.1007/BF03190187.

O’Sullivan, Mary J., Pamela J.J. Boyer, Gwendolyn B. Scott, Wade P. Parks, Stephen Weller, M. Robert Blum, James Balsley, and Yvonne J. Bryson. 1993. "The Pharmacokinetics and Safety of Zidovudine in the Third Trimester of Pregnancy for Women Infected with Human Immunodeficiency Virus and Their Infants: Phase I Acquired Immunodeficiency Syndrome Clinical Trials Group Study (Protocol 082).” American Journal of Obstetrics and Gynecology 168 (5): 1510-16. https://doi.org/10.1016/S0002-9378(11)90791-1.

Pearce, Robert G., R. Woodrow Setzer, Cory L. Strope, John F. Wambaugh, and Nisha S. Sipes. 2017. "Httk: R Package for High-Throughput Toxicokinetics." Journal of Statistical Software 79 (4): 1-26. https://doi.org/10.18637/jss.v079.i04.

Pham-The, Hai, Teresa Garrigues, Marival Bermejo, Isabel González-Álvarez, Maikel Cruz Monteagudo, and Miguel Ángel Cabrera-Pérez. 2013. "Provisional Classification and in Silico Study of Biopharmaceutical System Based on Caco-2 Cell Permeability and Dose Number." Molecular Pharmaceutics 10 (6): 2445-61. https://doi.org/10.1021/mp4000585.

Philippat, Claire, Marion Mortamais, Cécile Chevrier, Claire Petit, Antonia M Calafat, Xiaoyun Ye, Manori J Silva, et al. 2012. "Exposure to Phthalates and Phenols during Pregnancy and Offspring Size at Birth." Environmental Health Perspectives 120 (3): 464-70. https://doi.org/10.1289/ehp.1103634.

Philipson, Agneta, and Göran Stiernstedt. 1982. "Pharmacokinetics of Cefuroxime in Pregnancy." American Journal of Obstetrics and Gynecology 142 (7): 823-28. https://doi.org/10.1016/S0002-9378(16)32526-1.

R Core Team. 2018. "R: A Language and Environment for Statistical Computing." R Foundation for Statistical Computing, Vienna, Austria.

Rager, Julia E., Jacqueline Bangma, Celeste Carberry, Alex Chao, Jarod Grossman, Kun Lu, Tracy A. Manuck, Jon R. Sobus, John Szilagyi, and Rebecca C. Fry. 2020. "Review of the Environmental Prenatal Exposome and Its Relationship to Maternal and Fetal Health." Reproductive Toxicology, February. https://doi.org/10.1016/j.reprotox.2020.02.004.

Rappazzo, Kristen M, Evan Coffman, and Erin P Hines. 2017. "Exposure to Perfluorinated Alkyl Substances and Health Outcomes in Children: A Systematic Review of the Epidemiologic Literature." International Journal of Environmental Research and Public Health 14 (7): 691. https://doi.org/10.3390/ijerph14070691.

Ridd, Marianne J., Kenneth F. Brown, Roger L. Nation, and Clive B. Collier. 1989. "The Disposition and Placental Transfer of Diazepam in Cesarean Section." Clinical Pharmacology \& Therapeutics 45 (5): 506-12. https://doi.org/10.1038/clpt.1989.65.

Rivollier, Fabrice, Marie-Odile Krebs, and Oussama Kebir. 2019. "Perinatal Exposure to Environmental Endocrine Disruptors in the Emergence of Neurodevelopmental Psychiatric 
Diseases: A Systematic Review." International Journal of Environmental Research and Public Health 16 (8): 1318. https://doi.org/10.3390/ijerph16081318.

Ron, M., D. Hochner-Celnikier, J. Menczel, Z. Palti, and G. Kidroni. 1984. "Maternal-Fetal Transfer of Aminophylline." Acta Obstetricia et Gynecologica Scandinavica 63 (3): 217-18. https://doi.org/10.3109/00016348409155499.

Saghir, Shakil Ahmed, Sarosh Ahmed Khan, and Alene Theresa McCoy. 2012. "Ontogeny of Mammalian Metabolizing Enzymes in Humans and Animals Used in Toxicological Studies."

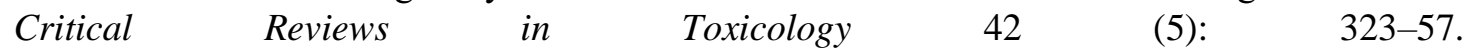
https://doi.org/10.3109/10408444.2012.674100.

Saitoh, Ryoichi, Kiyohiko Sugano, Noriyuki Takata, Tatsuhiko Tachibana, Atsuko Higashida, Yoshiaki Nabuchi, and Yoshinori Aso. 2004. "Correction of Permeability with Pore Radius of Tight Junctions in Caco-2 Monolayers Improves the Prediction of the Dose Fraction of Hydrophilic Drugs Absorbed by Humans." Pharmaceutical Research 21 (5): 749-55. https://doi.org/10.1023/B:PHAM.0000026423.48583.e2.

Saravanabhavan, Gurusankar, and Janine Murray. 2012. "Human Biological Monitoring of Diisononyl Phthalate and Diisodecyl Phthalate: A Review." Journal of Environmental and Public Health 2012: 810501-810501. https://doi.org/10.1155/2012/810501.

Schalkwijk, Stein, Aaron O. Buaben, Jolien J. M. Freriksen, Angela P. Colbers, David M. Burger, Rick Greupink, and Frans G. M. Russel. 2018. "Prediction of Fetal Darunavir Exposure by Integrating Human Ex-Vivo Placental Transfer and Physiologically Based Pharmacokinetic Modeling." Clinical Pharmacokinetics 57 (6): 705-16. https://doi.org/10.1007/s40262-0170583-8.

Schmitt, Walter. 2008. "General Approach for the Calculation of Tissue to Plasma Partition Coefficients." Toxicology in Vitro 22 (2): 457-67. https://doi.org/10.1016/j.tiv.2007.09.010.

Sharma, Raju Prasad, Marta Schuhmacher, and Vikas Kumar. 2018. "The Development of a Pregnancy PBPK Model for Bisphenol A and Its Evaluation with the Available Biomonitoring Data." Science of The Total Environment 624 (May): 55-68. https://doi.org/10.1016/j.scitotenv.2017.12.023.

Siu, Shing-Shun N., Matthew T. V. Chan, and Tze-Kin Lau. 2006. "Placental Transfer of Ondansetron during Early Human Pregnancy." Clinical Pharmacokinetics 45 (4): 419-23. https://doi.org/10.2165/00003088-200645040-00006.

Siu, Shing-Shun, John Hok-Keung Yeung, Man-Wah Pang, Pui Yu Chiu, and Tze Kin Lau. 2005. "Placental Transfer of Zidovudine in First Trimester of Pregnancy." Obstetrics \& Gynecology 106 (4): 824-27. https://doi.org/10.1097/01.aog.0000178160.38042.04.

Sobol', I.M., S. Tarantola, D. Gatelli, S.S. Kucherenko, and W. Mauntz. 2007. "Estimating the Approximation Error When Fixing Unessential Factors in Global Sensitivity Analysis." Reliability Engineering \& System Safety $92 \quad$ (7): 957-60. https://doi.org/10.1016/j.ress.2006.07.001.

Souza, Jacqueline de, Leslie Z. Benet, Yong Huang, and Sílvia Storpirtis. 2009. "Comparison of Bidirectional Lamivudine and Zidovudine Transport Using MDCK, MDCK-MDR1, and Caco-2 Cell Monolayers." Journal of Pharmaceutical Sciences 98 (11): 4413-19. https://doi.org/10.1002/jps.21744.

Stenberg, Patric, Ulf Norinder, Kristina Luthman, and Per Artursson. 2001. "Experimental and Computational Screening Models for the Prediction of Intestinal Drug Absorption." Journal of Medicinal Chemistry 44 (12): 1927-37. https://doi.org/10.1021/jm001101a.

Strikwold, Marije, Bert Spenkelink, Laura H. J. de Haan, Ruud A. Woutersen, Ans Punt, and Ivonne M. C. M. Rietjens. 2017. "Integrating in Vitro Data and Physiologically Based Kinetic (PBK) Modelling to Assess the in Vivo Potential Developmental Toxicity of a Series of Phenols." Archives of Toxicology 91 (5): 2119-33. https://doi.org/10.1007/s00204-016-1881-x.

Sunderland, Elsie M, Xindi C Hu, Clifton Dassuncao, Andrea K Tokranov, Charlotte C Wagner, and Joseph G Allen. 2019. "A Review of the Pathways of Human Exposure to Poly- and Perfluoroalkyl Substances (PFASs) and Present Understanding of Health Effects." Journal of Exposure Science \& Environmental Epidemiology 29 (2): 131-47. https://doi.org/10.1038/s41370-018-0094-1. 
Sweeney, Lisa M., Christopher R. Kirman, Shawn A. Gannon, Karla D. Thrall, Michael L. Gargas, and John H. Kinzell. 2009. "Development of a Physiologically Based Pharmacokinetic (PBPK) Model for Methyl Iodide in Rats, Rabbits, and Humans." Inhalation Toxicology 21 (6): 552-82. https://doi.org/10.1080/08958370802601569.

Syme, Michael R., James W. Paxton, and Jeffrey A. Keelan. 2004. "Drug Transfer and Metabolism by the Human Placenta." Clinical Pharmacokinetics $43 \quad$ (8): 487-514. https://doi.org/10.2165/00003088-200443080-00001.

Tamayo-Uria, Ibon, Léa Maitre, Cathrine Thomsen, Mark J. Nieuwenhuijsen, Leda Chatzi, Valérie Siroux, Gunn Marit Aasvang, et al. 2019. "The Early-Life Exposome: Description and Patterns in Six European Countries." Environment International 123 (February): 189-200. https://doi.org/10.1016/j.envint.2018.11.067.

Thomas, Simon, Frances Brightman, Helen Gill, Sally Lee, and Boris Pufong. 2008. "Simulation Modelling of Human Intestinal Absorption Using Caco-2 Permeability and Kinetic Solubility Data for Early Drug Discovery." Journal of Pharmaceutical Sciences 97 (10): 4557-74. https://doi.org/10.1002/jps.21305.

Unadkat, Jashvant D, Amber Dahlin, and Shashi Vijay. 2004. "Placental Drug Transporters." Current Drug Metabolism 5 (1): 125-31. https://doi.org/10.2174/1389200043489171.

Valcke, M., and K. Krishnan. 2011. "Evaluation of the Impact of the Exposure Route on the Human Kinetic Adjustment Factor." Regulatory Toxicology and Pharmacology 59 (2): 258-69. https://doi.org/10.1016/j.yrtph.2010.10.008.

Vandentorren, Stéphanie, Corinne Bois, Claudine Pirus, Hélène Sarter, Georges Salines, Henri Leridon, and Elfe team. 2009. "Rationales, Design and Recruitment for the Elfe Longitudinal Study." BMC Pediatrics 9 (September): 58-58. https://doi.org/10.1186/1471-2431-9-58.

Verner, Marc-André, Anne E Loccisano, Nils-Halvdan Morken, Miyoung Yoon, Huali Wu, Robin McDougall, Mildred Maisonet, et al. 2015. "Associations of Perfluoroalkyl Substances (PFAS) with Lower Birth Weight: An Evaluation of Potential Confounding by Glomerular Filtration Rate Using a Physiologically Based Pharmacokinetic Model (PBPK)." Environmental Health Perspectives 123 (12): 1317-24. https://doi.org/10.1289/ehp.1408837.

Verner, Marc-André, Robin McDougall, Anders Glynn, Melvin E Andersen, Harvey J Clewell 3rd, and Matthew P Longnecker. 2013. "Is the Relationship between Prenatal Exposure to PCB153 and Decreased Birth Weight Attributable to Pharmacokinetics?" Environmental Health Perspectives 121 (10): 1219-24. https://doi.org/10.1289/ehp.1206457.

Visser, A. A., and H. K. L. Hundt. 1984. "The Pharmacokinetics of a Single Intravenous Dose of Metronidazole in Pregnant Patients." Journal of Antimicrobial Chemotherapy 13 (3): 279-83. https://doi.org/10.1093/jac/13.3.279.

Walker, Natasha, Panagiotis Filis, Ugo Soffientini, Michelle Bellingham, Peter J O'Shaughnessy, and Paul A Fowler. 2017. "Placental Transporter Localization and Expression in the Human: The Importance of Species, Sex, and Gestational Age Differences $\dagger$.” Biology of Reproduction 96 (4): 733-42. https://doi.org/10.1093/biolre/iox012.

Wild, Christopher Paul. 2005. "Complementing the Genome with an 'Exposome': The Outstanding Challenge of Environmental Exposure Measurement in Molecular Epidemiology." Cancer Epidemiology Biomarkers \&amp;Amp; Prevention 14 (8): 1847. https://doi.org/10.1158/10559965.EPI-05-0456.

Willmann, Stefan, Walter Schmitt, Jörg Keldenich, and Jennifer B. Dressman. 2003. "A Physiologic Model for Simulating Gastrointestinal Flow and Drug Absorption in Rats." Pharmaceutical Research 20 (11): 1766-71. https://doi.org/10.1023/B:PHAM.0000003373.72652.c0.

Yazdanian, Mehran, Susan L. Glynn, James L. Wright, and Amale Hawi. 1998. "Correlating Partitioning and Caco-2 Cell Permeability of Structurally Diverse Small Molecular Weight Compounds." Pharmaceutical Research $15 \quad$ (9): 1490-94. https://doi.org/10.1023/A:1011930411574.

Yee, Shiyin. 1997. "In Vitro Permeability Across Caco-2 Cells (Colonic) Can Predict In Vivo (Small Intestinal) Absorption in Man-Fact or Myth.” Pharmaceutical Research 14 (6): 763-66. https://doi.org/10.1023/A:1012102522787.

Yoon, Miyoung, Jeffry D. Schroeter, Andy Nong, Michael D. Taylor, David C. Dorman, Melvin E. Andersen, and Harvey J. Clewell III. 2011. "Physiologically Based Pharmacokinetic Modeling 
of Fetal and Neonatal Manganese Exposure in Humans: Describing Manganese Homeostasis during Development." Toxicological Sciences $122 \quad$ (2): 297-316. https://doi.org/10.1093/toxsci/kfr141.

Yun, Yejin Esther, Cecilia A. Cotton, and Andrea N. Edginton. 2014. "Development of a Decision Tree to Classify the Most Accurate Tissue-Specific Tissue to Plasma Partition Coefficient Algorithm for a given Compound." Journal of Pharmacokinetics and Pharmacodynamics 41 (1): 1-14. https://doi.org/10.1007/s10928-013-9342-0.

Zhang, Zufei, Marjorie Z. Imperial, Gabriela I. Patilea-Vrana, Janak Wedagedera, Lu Gaohua, and Jashvant D. Unadkat. 2017. "Development of a Novel Maternal-Fetal Physiologically Based Pharmacokinetic Model I: Insights into Factors That Determine Fetal Drug Exposure through Simulations and Sensitivity Analyses." Drug Metabolism and Disposition: The Biological Fate of Chemicals 45 (8): 920-38. https://doi.org/10.1124/dmd.117.075192.

Zhang, Zufei, and Jashvant D. Unadkat. 2017. "Verification of a Maternal-Fetal Physiologically Based Pharmacokinetic Model for Passive Placental Permeability Drugs." Drug Metabolism and Disposition 45 (8): dmd.116.073957. https://doi.org/10.1124/dmd.116.073957. 


\section{FIGURES}

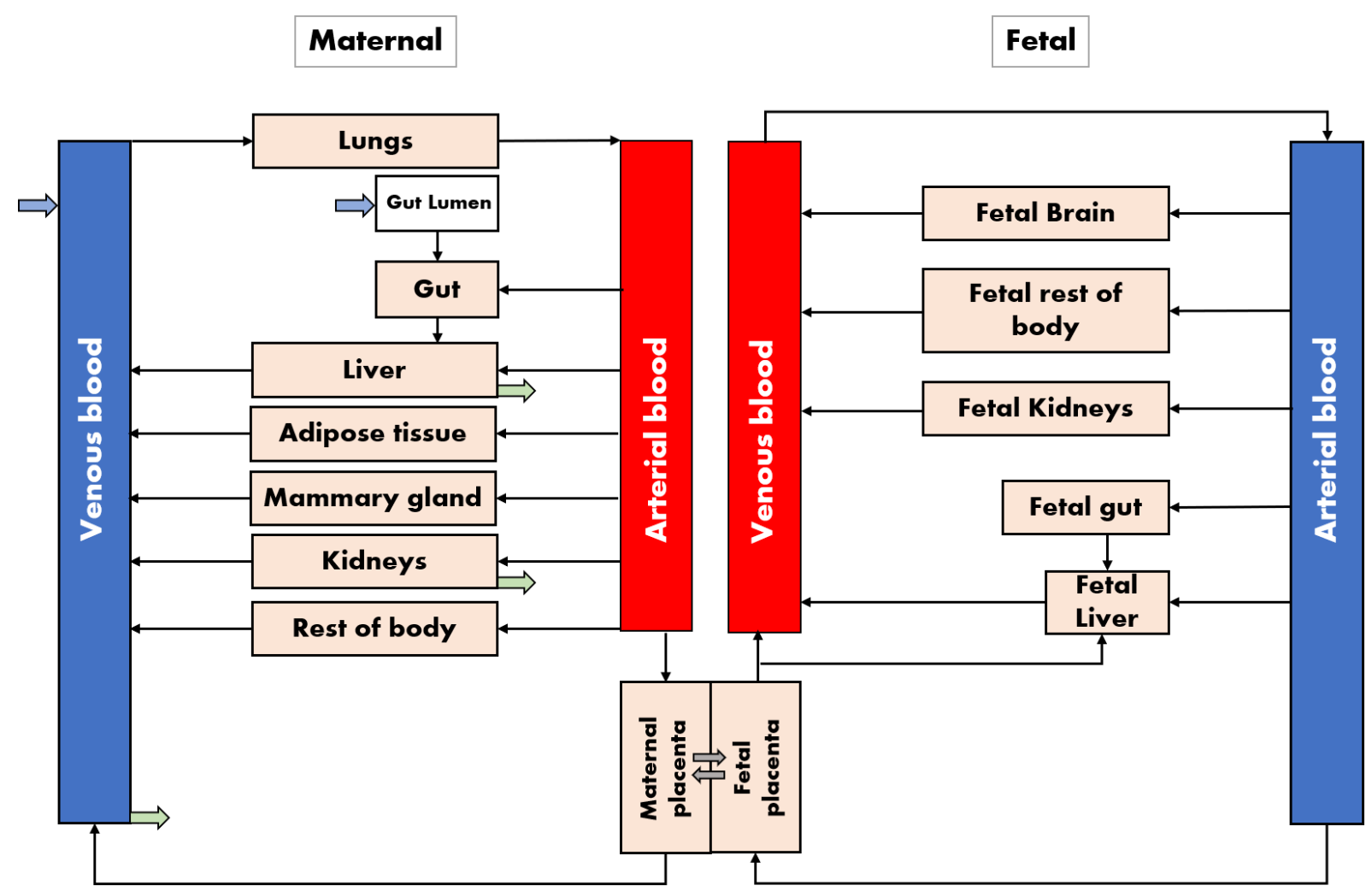

Figure 1: Schematic representation of the pPBPK model. Blue arrows represent the administration sites, green arrows the elimination pathways, and grey arrows the placental passive diffusion. 

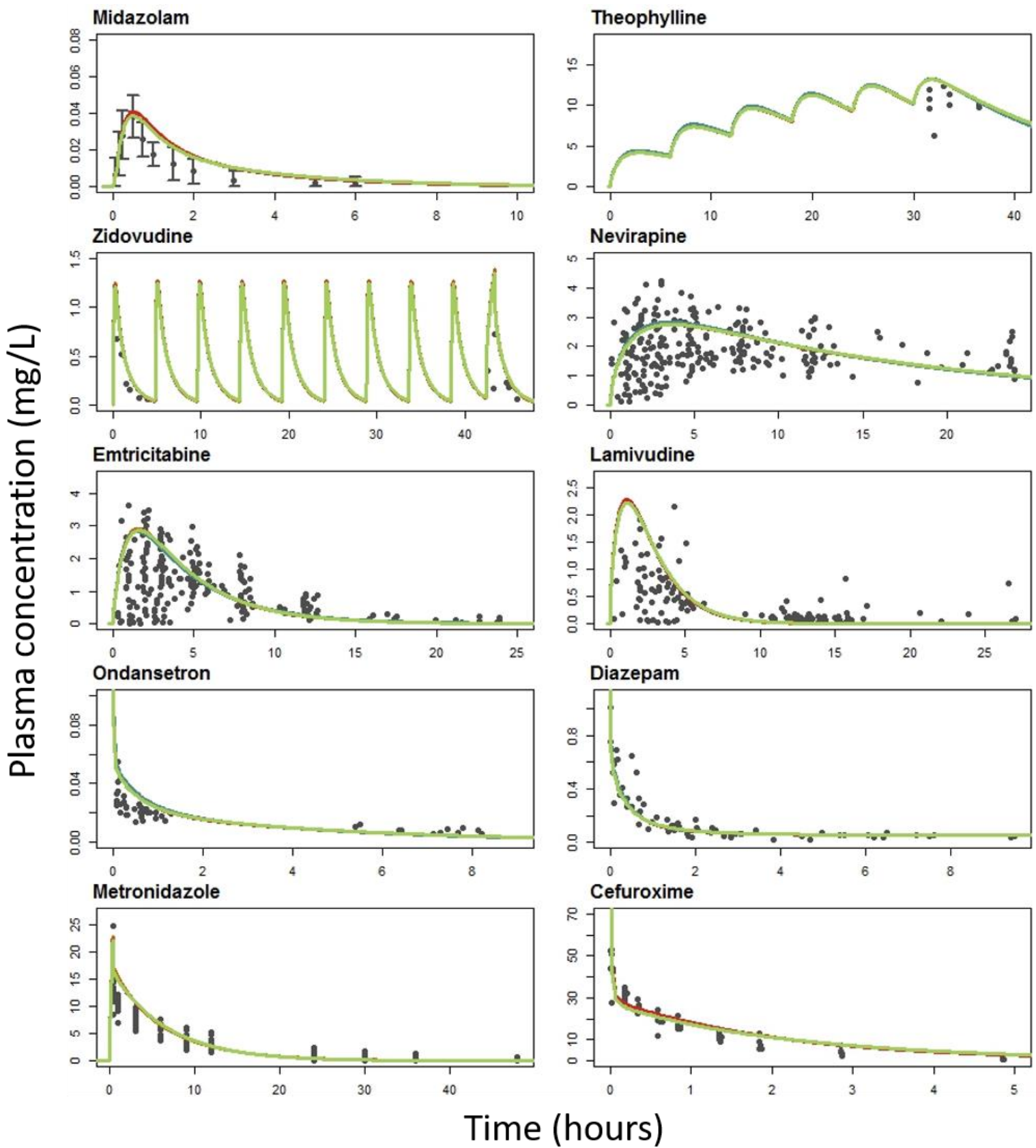

Figure 2: Plasma concentration-time profiles of the ten substances in pregnant women at term. The black dots stand for the measured concentrations, and the solid lines for the predicted mean plasma concentration according to the four placental transfer models: SE model in orange; InV model in red; PL model in green; ExV model in blue. See Table 1 for the posology and Figure S4 for semi-logarithmic plots. 


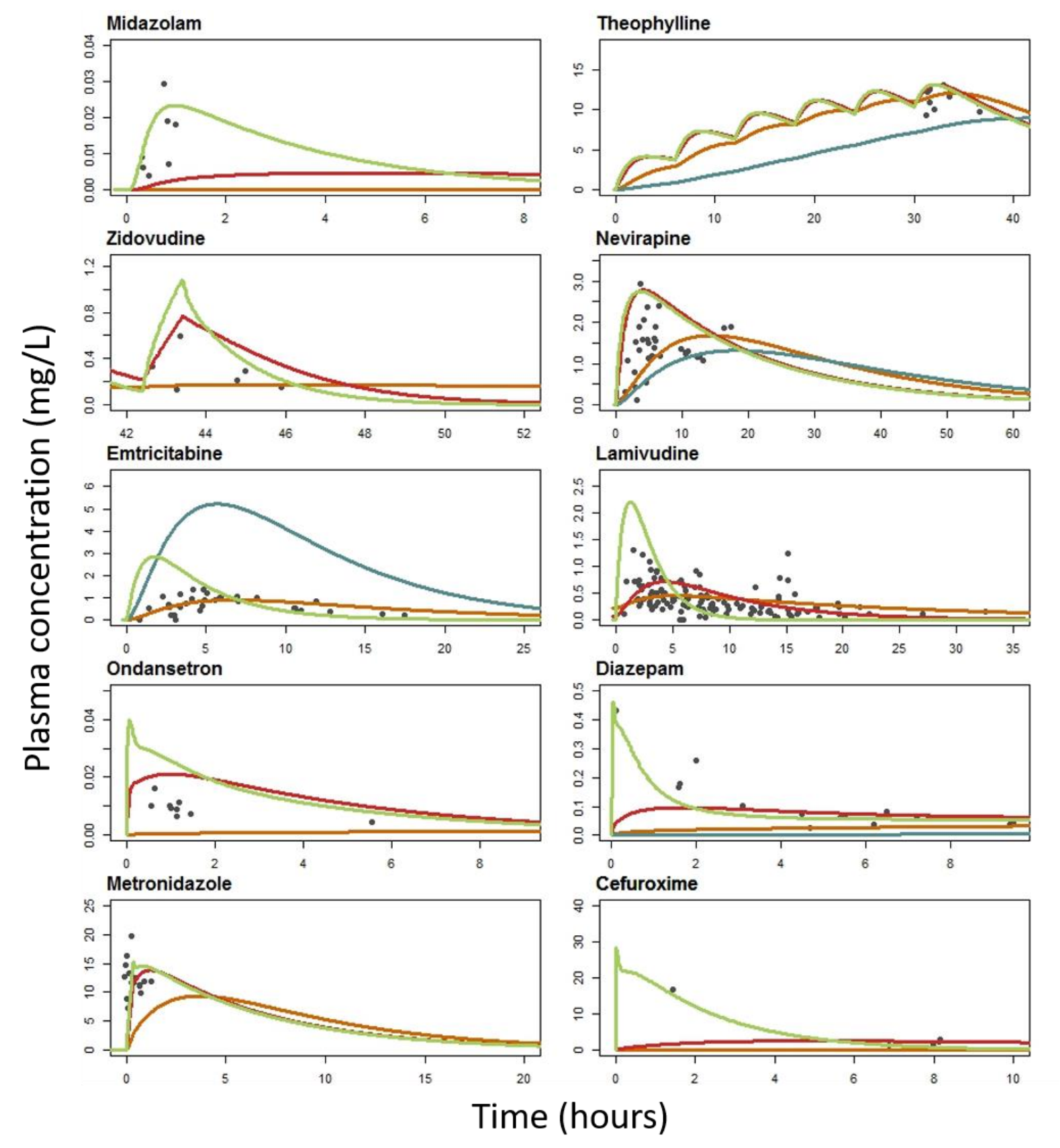

Figure 3: Umbilical cord plasma concentration-time profiles of the ten tested substances. The black dots stand for the measured concentrations. The solid lines represent the predicted mean plasma concentration according to the four placental transfer models: $S E$ model in orange; InV model in red; $P L$ model in green; $E x V$ model in blue. See Table 1 for the posology and Figure S5 for semi-logarithmic plots. 


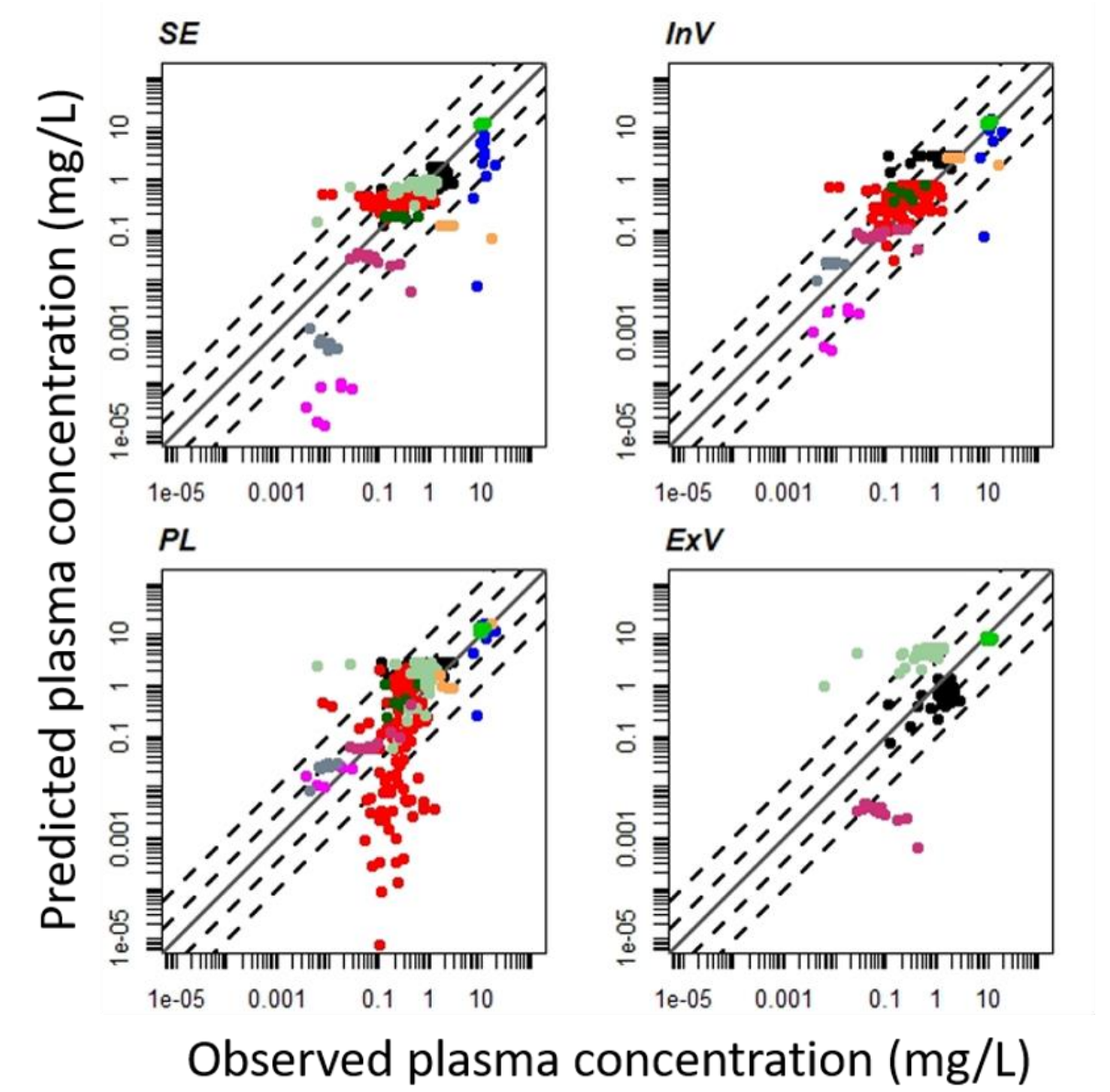

NEVI $\square$ LAMI $\square$ ZIDO $\square$ MNZ $\square$ EMTRI $\square$ MDZ $\square$ CEFU $\square$ DZP $\square$ OND $\square$ THEO

Figure 4: Goodness-of-fit plot for the fetal plasma concentrations. The panels stand for the four placental transfer models ( $S E$ model in top left, InV model in top right, $P L$ model in bottom left and $E x V$ model in bottom right). The solid line indicates the line of identity and the dashed lines the three-fold and the ten-fold error ranges. 


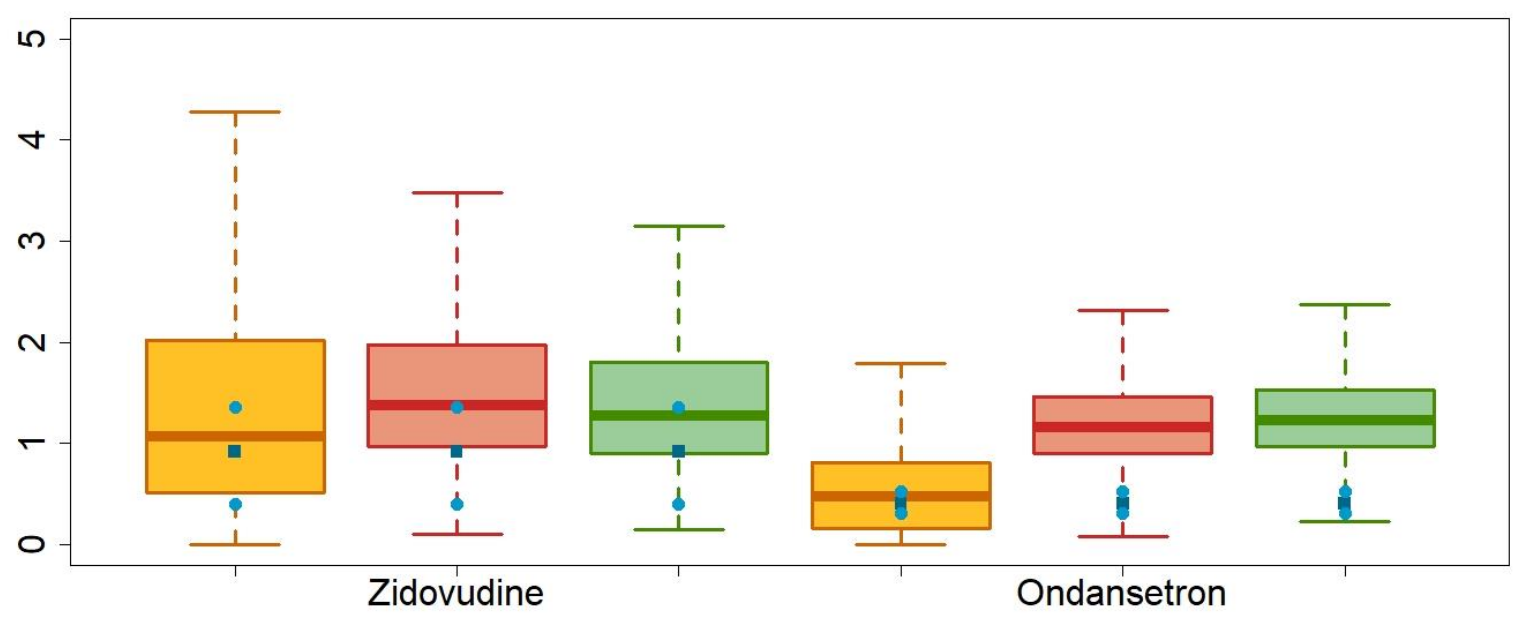

Figure 5: Boxplots of the simulated ratios between the total concentration in fetus and the maternal plasma concentration, together with the data during the first trimester of pregnancy. 10,000 Monte Carlo simulations were performed with the pPBPK with the $S E$ (orange), InV (red) and $P L$ (green) models. The dark blue squares stand for the median observed ratios and the light blue circles for the associated IQR.
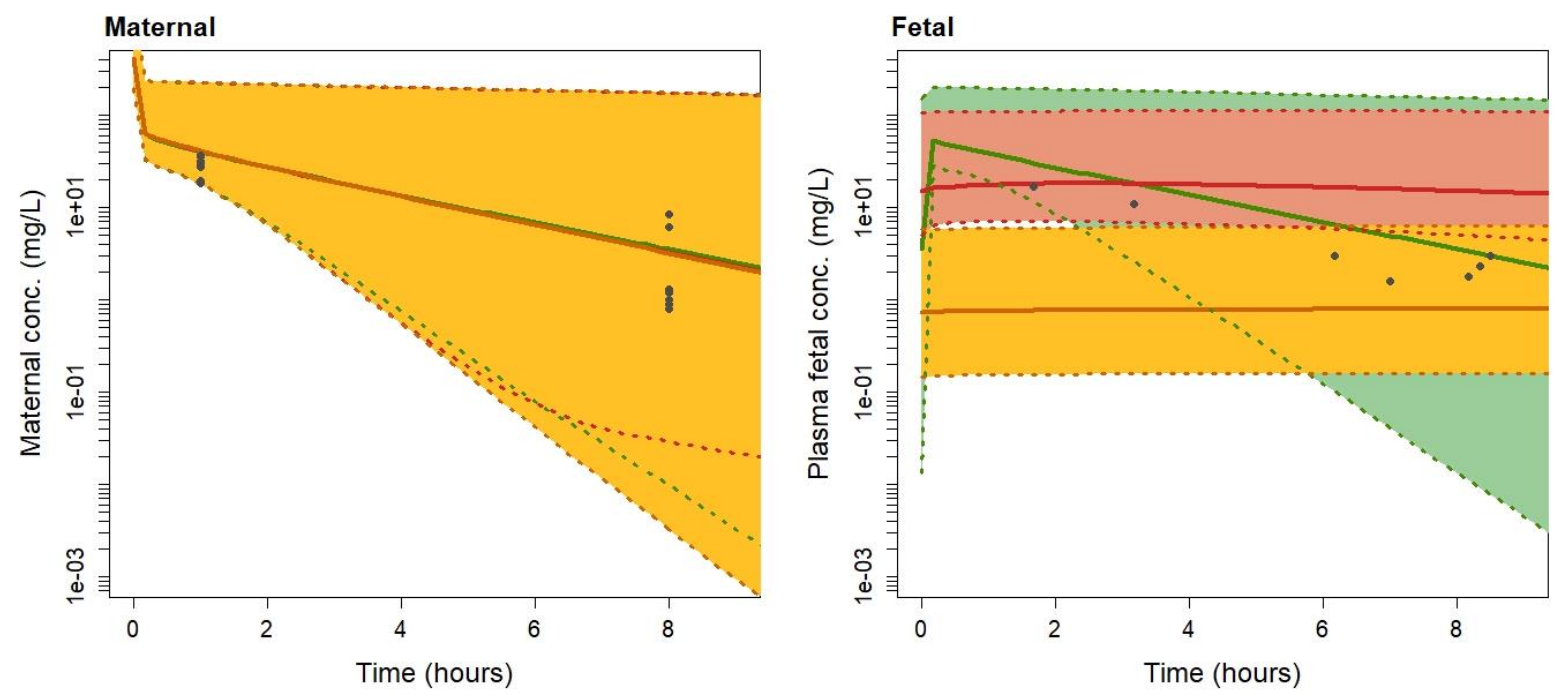

Figure 6: Simulated (lines) and oberved (circles) cefuroxime concentration-time profiles in maternal plasma (left window) and venous umbilical cord plasma (right window) in early third trimester after the intravenous administration of $1,500 \mathrm{mg}$ three times a day predicted by the $S E$ (orange), InV (red) and $P L$ (green) models. The shaded area indicates the predicted $95^{\text {th }}$ confidence interval. The solid lines stand for the MC simulated median profiles and the dotted lines delimit the intervals of uncertainty for each model. 

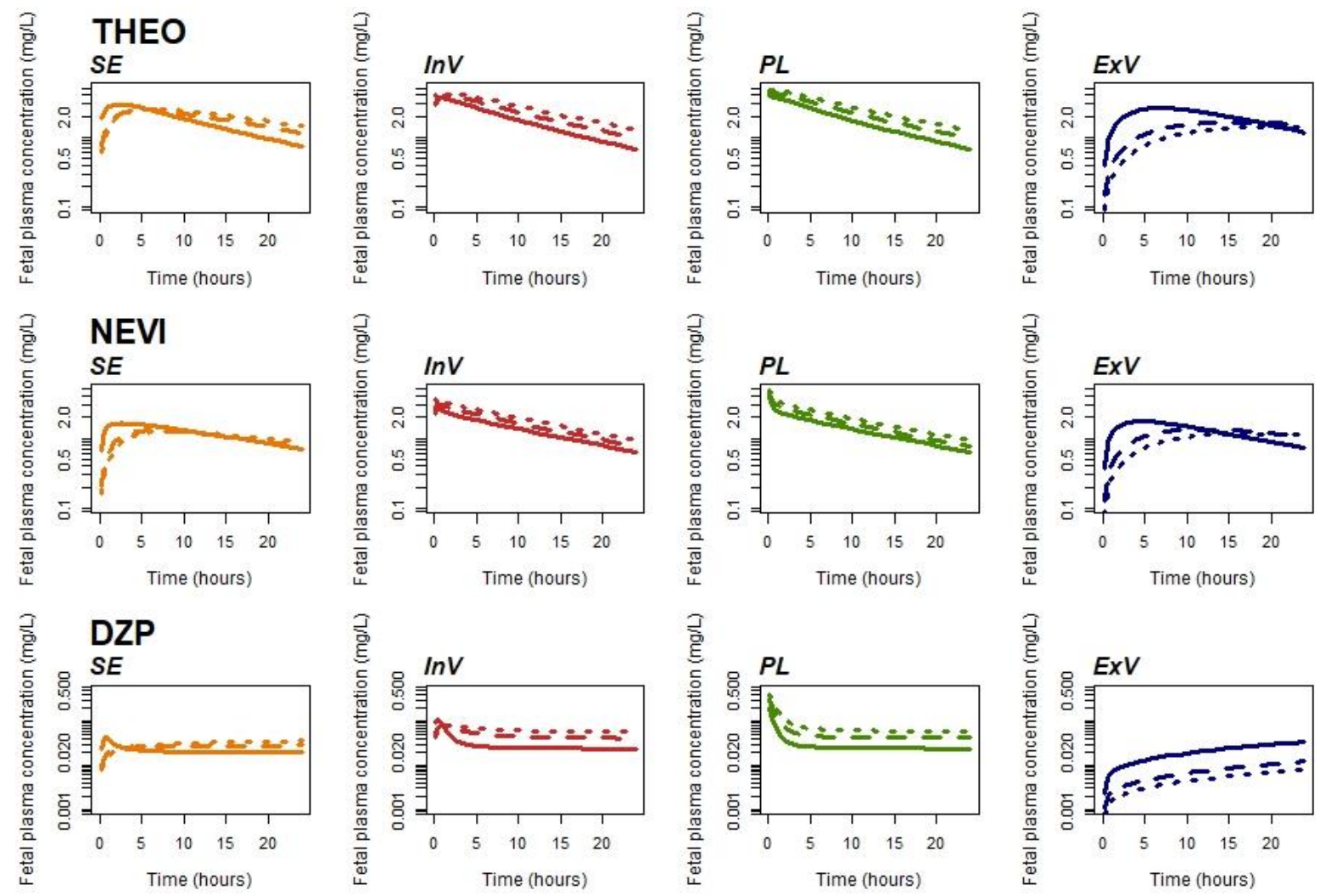

Figure 7: Predicted fetal plasma concentrations of THEO, NEVI and DZP after an oral administration of 160,200 , and $10 \mathrm{mg}$, respectively, to the mother at the end of the three trimesters of pregnancy. The simulations were conducted with the $S E, I n V, P L$ and $E x V$ models. Only the median profiles obtained from the Monte Carlo simulations are presented. The solid lines are used for the first trimester profiles, the dashed lines for the second trimester and the dotted lines for the third trimester. 
TABLES

Table 1: Summary of the experimental studies used for the pPBPK model evaluation at the end of pregnancy

\begin{tabular}{lcccccll}
\hline Compound & No. of women & BW (kg) & FW (weeks) & Admin. & Dose (mg) & Dosing & Reference \\
\hline MDZ & 11 & 69 & $36-39^{\alpha}$ & PO & 15 & SD & (Kanto et al. 1983) \\
THEO & 10 & 72.7 & 38 & PO & 160 & MD & (Ron et al. 1984) \\
ZIDO & 26 & $-\beta$ & 8.6 & PO & 200 & MD & (S.-S. Siu et al. 2005) \\
& 7 & $60-110^{\gamma}$ & $36-39^{\alpha}$ & PO/Inf & $200 / 140$ & MD & (O'Sullivan et al. 1993) \\
NEVI & 38 & 58.3 & 37 & PO & 200 & SD & (Benaboud et al. 2011) \\
EMTRI & 38 & 58.3 & 37 & PO & 400 & SD & (Hirt et al. 2009) \\
LAMI & 123 & 73.5 & 36 & PO & 300 & MD & (Benaboud et al. 2012) \\
OND & 41 & 55.2 & 8.5 & PO & 8 & MD & (S.-S. N. Siu, Chan, and Lau 2006) \\
& 10 & 80.7 & 37 & IV & 4 & SD & (Elkomy et al. 2015) \\
DZP & - & $72.3^{\eta}$ & $38^{\alpha}$ & IV & 10 & SD & (Mandelli et al. 1975; Moore and \\
MNZ & 10 & 57.7 & 6.8 & Inf & 500 & SD & (Karhunen 1984) \\
& 16 & $-\beta$ & $38^{\alpha}$ & Inf & 500 & SD & (Visser and Hundt 1984) \\
CEFU & 9 & 70.9 & 28.2 & IV & 1500 & MD & (De Leeuw et al. 1993) \\
& 7 & 74 & 39 & IV & 750 & SD & (Philipson and Stiernstedt 1982)
\end{tabular}

SD: single dose; MD: multiple doses; IV: intravenous; PO: per os; Inf: infusion; ${ }^{\alpha}$ default value; ${ }^{\beta} B W_{0}$ set as $60 \mathrm{~kg}$ (default value) in the model; ${ }^{\gamma} B W$ set as $70 \mathrm{~kg}$

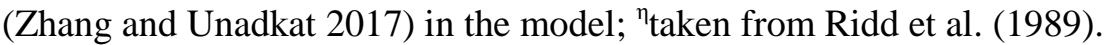


Table 2: Values of the compound-specific parameters of the pPBPK model for the ten compounds of our study.

\begin{tabular}{|c|c|c|c|c|c|c|c|c|}
\hline Compound & $\begin{array}{l}\text { kgutabs } \quad\left(\mathrm{h}^{-}\right. \\
\left.{ }_{1}\right)\end{array}$ & $F$ & $f u$ & $R b p$ & $C L_{m e t}(\mathrm{~L} / \mathbf{h} / \mathbf{k g})$ & $\begin{array}{l}C \boldsymbol{L}_{r c} \\
(\mathbf{L} / \mathbf{h})\end{array}$ & $\begin{array}{l}C \boldsymbol{L}_{\text {sysc }} \\
(\mathrm{L} / \mathbf{h})\end{array}$ & Reference \\
\hline MDZ & 4 & $0.51^{\alpha}$ & 0.032 & 0.66 & $20.76^{\mathrm{a}}$ & $0.085^{*}$ & - & (Zhang and Unadkat 2017) \\
\hline THEO & 1 & $0.97^{\alpha}$ & 0.58 & 0.82 & $0.044^{\mathrm{b}}$ & $0.45^{*}$ & - & (Zhang and Unadkat 2017) \\
\hline ZIDO & 4.05 & $0.83^{\alpha}$ & 0.8 & 0.91 & $0.41^{\mathrm{b}}$ & $15.5^{*}$ & 52.8 & (Zhang and Unadkat 2017) \\
\hline NEVI & 0.67 & $0.60^{\beta}$ & 0.4 & 1.04 & $0.054^{\mathrm{a}}$ & 0.07 & - & (De Sousa Mendes et al. 2017) \\
\hline EMTRI & $0.27^{1}$ & 0.93 & 0.96 & 1 & $0.096^{\mathrm{a}}$ & 13 & - & (De Sousa Mendes et al. 2016) \\
\hline LAMI & $1.04^{2}$ & 0.85 & 0.84 & 1.5 & $0.162^{\mathrm{a}}$ & 16.8 & - & (De Sousa Mendes et al. 2015) \\
\hline OND & 1.05 & 1 & 0.27 & 1.16 & $1.55^{\mathrm{a}, \mathrm{c}}$ & $F_{G F R}$ & - & $\begin{array}{l}\text { (Dallmann, Ince, et al. 2018) } \\
\text { (Hsyu et al. (1994) }\end{array}$ \\
\hline DZP & - & - & 0.02 & 0.59 & $3.88^{\mathrm{a}, \mathrm{c}}$ & $F_{G F R}$ & - & (Dallmann, Ince, et al. 2018) \\
\hline MNZ & - & - & 0.89 & 0.82 & $0.056^{\mathrm{a}, \mathrm{c}}$ & 0.49 & - & (Dallmann, Ince, et al. 2018) \\
\hline CEFU & - & - & 0.67 & 0.78 & - & 11.9 & - & $\begin{array}{l}\text { (Dallmann, Ince, Solodenko, et } \\
\text { al. 2017) }\end{array}$ \\
\hline
\end{tabular}

${ }^{1}$ Set as $50 \%$ of the published value based on visual fitting. ${ }^{2}$ Estimated with non-pregnant and pregnant women mixed data. ${ }^{\alpha}$ Product of the fraction absorbed and the fraction escaping gut metabolism. ${ }^{\beta}$ Set as $50 \%$ of the published value based on visual fitting. ${ }^{\mathrm{a}}$ Calculated with the well-stirred liver model using an hepatic plasma flow of $53.91 \mathrm{~L} / \mathrm{h}$ for a $60 \mathrm{~kg}$ woman. ${ }^{\mathrm{b}} \mathrm{The}$ intrinsic hepatic unbound clearance was corrected by fup and scaled to a $60 \mathrm{~kg}$ woman. ${ }^{\mathrm{c}} \mathrm{CLiv}$ was computed as Dose/AUC observed for a non-pregnant woman. *CLrc not scaled to $F_{G F R}$ variations. 
Table 3: Values of the placental transfer-specific parameters of the pPBPK model for the ten compounds of our study. For six compounds, no values for $k d_{m p: f p}$ and $k d_{f p: m p}(E x V$ model) were available. For the $I n V$ model, no Papp values for EMTRI were available.

\begin{tabular}{|c|c|c|c|c|c|c|c|}
\hline Compound & Parameter & Value & Reference & Compound & Parameter & Value & Reference \\
\hline \multirow[t]{5}{*}{ MDZ } & $\log M A$ & 2.24 & (Zhang and Unadkat 2017) & \multirow[t]{5}{*}{ THEO } & $\log M A$ & 1.28 & (Zhang and Unadkat 2017) \\
\hline & $M W e f f\left(\mathrm{~g} \cdot \mathrm{mol}^{-1}\right)$ & 286.8 & (Zhang and Unadkat 2017) & & $M W e f f\left(\mathrm{~g} \cdot \mathrm{mol}^{-1}\right)$ & 180.2 & (Zhang and Unadkat 2017) \\
\hline & $\operatorname{Papp}\left(\mathrm{nm} \cdot \mathrm{s}^{-1}\right)$ & 489.9 & (Zhang and Unadkat 2017) & & $\operatorname{Papp}\left(\mathrm{nm} \cdot \mathrm{s}^{-1}\right)$ & 335.5 & (Zhang and Unadkat 2017) \\
\hline & $k d_{m p: f p}\left(\min ^{-1}\right)$ & - & & & $k d_{m p: f p}\left(\min ^{-1}\right)$ & 0.00094 & (Omarini et al. 1993) \\
\hline & $k d_{f p: m p}\left(\min ^{-1}\right)$ & - & & & $k d_{f p: m p}\left(\min ^{-1}\right)$ & 0.00153 & (Omarini et al. 1993) \\
\hline \multirow[t]{5}{*}{ ZIDO } & $\log M A$ & 1.31 & (Zhang and Unadkat 2017) & \multirow[t]{5}{*}{ NEVI } & $\log M A$ & 1.88 & (De Sousa Mendes et al. 2017) \\
\hline & $M W e f f\left(\mathrm{~g} \cdot \mathrm{mol}^{-1}\right)$ & 267.2 & (Zhang and Unadkat 2017) & & $M W e f f\left(\right.$ g. $\left.\mathrm{mol}^{-1}\right)$ & 266 & (De Sousa Mendes et al. 2017) \\
\hline & $\operatorname{Papp}\left(\mathrm{nm} \cdot \mathrm{s}^{-1}\right)$ & 212.4 & (Zhang and Unadkat 2017) & & $\operatorname{Papp}\left(\mathrm{nm} \cdot \mathrm{s}^{-1}\right)$ & 301 & (Yazdanian et al. 1998) \\
\hline & $k d_{m p: f p}\left(\min ^{-1}\right)$ & - & & & $k d_{m p: f p}\left(\min ^{-1}\right)$ & 0.00128 & (De Sousa Mendes et al. 2017) \\
\hline & $k d_{f p: m p}\left(\min ^{-1}\right)$ & - & & & $k d_{f p: m p}\left(\min ^{-1}\right)$ & 0.00106 & (De Sousa Mendes et al. 2017) \\
\hline \multirow[t]{5}{*}{ EMTRI } & $\log M A$ & 1.16 & (De Sousa Mendes et al. 2016) & \multirow[t]{5}{*}{ LAMI } & $\log M A$ & 1.04 & \\
\hline & $M W e f f\left(\mathrm{~g} \cdot \mathrm{mol}^{-1}\right)$ & 230.25 & (De Sousa Mendes et al. 2016) & & $M W e f f\left(\mathrm{~g} \cdot \mathrm{mol}^{-1}\right)$ & 229 & (Benaboud et al. 2012) \\
\hline & $\operatorname{Papp}\left(\mathrm{nm} \cdot \mathrm{s}^{-1}\right)$ & - & & & $\operatorname{Papp}\left(\mathrm{nm} \cdot \mathrm{s}^{-1}\right)$ & 12 & (de Souza et al. 2009) \\
\hline & $k d_{m p: f p}\left(\min ^{-1}\right)$ & 0.00724 & (De Sousa Mendes et al. 2016) & & $k d_{m p: f p}\left(\min ^{-1}\right)$ & - & \\
\hline & $k d_{f p: m p}\left(\min ^{-1}\right)$ & 0.00132 & (De Sousa Mendes et al. 2016) & & $k d_{f p: m p}\left(\min ^{-1}\right)$ & - & \\
\hline \multirow[t]{5}{*}{ OND } & $\log M A$ & 2.08 & & \multirow[t]{5}{*}{ MNZ } & $\log M A$ & 1.28 & \\
\hline & $M W e f f\left(\mathrm{~g} \cdot \mathrm{mol}^{-1}\right)$ & 293 & (Dallmann, Ince, et al. 2018) & & $M W e f f\left(\mathrm{~g} \cdot \mathrm{mol}^{-1}\right)$ & 171 & (Dallmann, Ince, et al. 2018) \\
\hline & $\operatorname{Papp}\left(\mathrm{nm} \cdot \mathrm{s}^{-1}\right)$ & 1100 & (Irvine et al. 1999) & & $\operatorname{Papp}\left(\mathrm{nm} \cdot \mathrm{s}^{-1}\right)$ & 481 & (Cherian et al. 2015) \\
\hline & $k d_{m p: f p}\left(\min ^{-1}\right)$ & - & & & $k d_{m p: f p}\left(\min ^{-1}\right)$ & - & \\
\hline & $k d_{f p: m p}\left(\min ^{-1}\right)$ & - & & & $k d_{f p: m p}\left(\min ^{-1}\right)$ & - & \\
\hline \multirow[t]{5}{*}{ DZP } & $\log M A$ & 2.76 & & \multirow[t]{5}{*}{ CEFU } & $\log M A$ & 1.30 & \multirow{5}{*}{$\begin{array}{l}\text { (Dallmann, Ince, Solodenko, et } \\
\text { al. 2017) } \\
\text { (Saitoh et al. 2004) }\end{array}$} \\
\hline & $M W e f f\left(\mathrm{~g} \cdot \mathrm{mol}^{-1}\right)$ & 263 & (Dallmann, Ince, et al. 2018) & & $M W e f f\left(\mathrm{~g} \cdot \mathrm{mol}^{-1}\right)$ & 424 & \\
\hline & $\operatorname{Papp}\left(\mathrm{nm} \cdot \mathrm{s}^{-1}\right)$ & 639 & $\begin{array}{l}\text { (Yazdanian et al. 1998; Yee } \\
\text { 1997; Thomas et al. 2008; } \\
\text { Stenberg et al. 2001; Garberg } \\
\text { et al. 2005; Neuhaus et al. } \\
\text { 2006) }\end{array}$ & & $\operatorname{Papp}\left(\mathrm{nm} \cdot \mathrm{s}^{-1}\right)$ & 4.95 & \\
\hline & $k d_{m p: f p}\left(\min ^{-1}\right)$ & 0.0188 & $\begin{array}{l}\text { (Myllynen and Vähäkangas } \\
2002\end{array}$ & & $k d_{m p: f p}\left(\min ^{-1}\right)$ & - & \\
\hline & $k d_{f p: m p}\left(\min ^{-1}\right)$ & 0.00008 & $\begin{array}{l}\text { (Myllynen and Vähäkangas } \\
2002\end{array}$ & & $k d_{f p: m p}\left(\min ^{-1}\right)$ & - & \\
\hline
\end{tabular}


Table 4: Maximum maternal plasma concentrations $(\mathrm{Cmax})$ at the corresponding time (Tmax) predicted by the perfusion-limited model for the placental transfers (PL model). The predictions correspond to the central value obtained by a deterministic simulation and the $95 \%$ interval of confidence obtained with the MC simulations. The relative error compared to the observed value is also given in percent.

\begin{tabular}{lllll}
\hline \multirow{2}{*}{ Compound } & \multicolumn{2}{c}{ Cmax $(\mathbf{m g} / \mathbf{L})$} & \multicolumn{2}{c}{ Tmax $(\mathbf{h})$} \\
& Obs & Pred $(\mathbf{R E}(\%))$ & Obs & Pred $(\mathbf{R E}(\%))$ \\
\hline MDZ & 0.038 & $0.038[0.008-0.103](0)$ & 0.5 & $0.52[0.17-1.83](4)$ \\
THEO & 12.26 & $13.15[5.17-55.53](7.2)$ & 3 & $1.75[0.67-4.67](-41.7)$ \\
ZIDO & 0.72 & $1.35[0.92-4.65](87.5)$ & 0.93 & $0.98[0.83-1](5.4)$ \\
NEVI & 2.94 & $2.75[1.01-9.61](-6.5)$ & 3.8 & $3.65[1-12.83](-3.9)$ \\
EMTRI & 3.61 & $2.86[0.85-17.66](-20.8)$ & 0.96 & $1.65[1-5.33](71.9)$ \\
LAMI & 2.15 & $2.22[0.97-10.94](3.2)$ & 4.29 & $1.15[0.5-3.5](-73.2)$ \\
\hline
\end{tabular}


Table 5: Predictions of the maximum fetal plasma concentration $\left(\mathrm{Cmax}_{f e t}\right)$ at the corresponding time $\left(\operatorname{Tmax}_{f e t}\right)$ according to the four placental transfer models. The observations and the predicted median value are reported together with the $95 \%$ confidence interval.

\begin{tabular}{|c|c|c|c|c|c|}
\hline Compound & Obs & SE model & InV model & PL model & ExV model \\
\hline \multicolumn{6}{|l|}{$\operatorname{Cmax}_{\text {fet }}$} \\
\hline MDZ & 0.030 & $0.0002[2.8 \mathrm{E}-6 ; 0.015]$ & 0.0049 [7.85 E-4;0.02] & $0.023[0.005 ; 0.075]$ & - \\
\hline THEO & 13.01 & $12.06[3.43 ; 50.42]$ & 13.10 [4.99;58.15] & $13.09[5.13 ; 58.72]$ & $8.94[0.99 ; 41.45]$ \\
\hline ZIDO & 0.59 & $0.17[0.016 ; 1.07]$ & $0.77[0.45 ; 3.34]$ & $1.08[0.74 ; 4.53]$ & - \\
\hline NEVI & 2.94 & $1.68[0.06 ; 6.55]$ & $2.78[0.97-10.14]$ & $2.75[1 ; 10.59]$ & $1.32[0.12 ; 3.97]$ \\
\hline EMTRI & 1.38 & $0.90[0.16 ; 7.44]$ & - & $2.84[0.86 ; 18.93]$ & $5.21[0.82 ; 35.96]$ \\
\hline LAMI & 1.31 & $0.46[0.22 ; 3.66]$ & $0.72[0.3 ; 4.32]$ & $2.20[0.94 ; 11.61]$ & - \\
\hline OND & 0.016 & $0.0013[2.4 \mathrm{E}-5 ; 0.026]$ & 0.021 [8.17 E;7;0.027] & $0.04[0.02 ; 0.08]$ & - \\
\hline DZP & 0.43 & 0.04 [2.4 E-4;0.44] & $0.09[0.02 ; 0.28]$ & $0.46[0.26 ; 0.99]$ & $0.0084[4.7$ E-4;0.02] \\
\hline MNZ & 19.7 & $9.37[3.13 ; 48.56]$ & $13.85[0.05 ; 46.63]$ & $15.38[10.97 ; 76.42]$ & - \\
\hline CEFU & 17 & $0.12[0.006 ; 0.23]$ & $2.66[0.48 ; 9.78]$ & $28.47[16.88 ; 53.81]$ & - \\
\hline \multicolumn{6}{|l|}{$\operatorname{Tmax}_{f e t}$} \\
\hline MDZ & 0.75 & $>12$ & $4.75[1.33 ; 18.67]$ & 0.98 [0.5;4.17] & - \\
\hline THEO & 3 & $4[2 ; 24]$ & $2.35[1.5 ; 6.33]$ & $2[1.17 ; 5]$ & $>12$ \\
\hline ZIDO & 0.93 & $2.68[1.0 ; 23.5]$ & $1.03[1.00 ; 2.67]$ & $1.02[1.00 ; 1.02]$ & - \\
\hline NEVI & 3.8 & $>12$ & $4.2[1.83 ; 15.5]$ & $3.77[1.33 ; 13.17]$ & $>12$ \\
\hline EMTRI & 4.2 & $6.8[2.67 ; 24]$ & - & $1.77[1.17 ; 5.33]$ & $5.72[3.67 ; 19.17]$ \\
\hline LAMI & 1.55 & $5.25[2.67 ; 1]$ & $4.35[2.67 ; 9.5]$ & $1.3[0.67 ; 3.67]$ & - \\
\hline OND & 0.63 & $>12$ & $0.95[0.33 ; 24]$ & $0.083[0.03 ; 0.52]$ & - \\
\hline DZP & 0.1 & $>12$ & $1.68[0.5 ; 24]$ & $0.033[0.03 ; 0.13]$ & $>12$ \\
\hline MNZ & 0.25 & $3.68[0.66 ; 14.67]$ & $1.2[0.33 ; 24]$ & $0.35[0.35 ; 1.25]$ & - \\
\hline CEFU & 1.6 & $11.35[5 ; 24]$ & $5.1[2 ; 24]$ & $0.18[0.03 ; 0.87]$ & - \\
\hline
\end{tabular}


Table 6: Maximal concentration in fetal plasma $\left(\operatorname{Cmax}_{\text {fet }}\right)$ and the area under the curve $24 \mathrm{~h}$ after the administration $\left(A U C_{24 f e t}\right)$ predicted by the $S E$, InV,PL and $E x V$ models following a maternal exposure to THEO (160 $\mathrm{mg}$ per os), NEVI (200 $\mathrm{mg}$ per os) and DZP (10 mg per os). The median values are given at each trimester. The $K_{m p: f p}$ (and Kfp:mp for the $E x V$ model) values are given for each model.

\begin{tabular}{|c|c|c|c|c|c|c|c|c|c|c|}
\hline \multirow[b]{2}{*}{ Compound } & \multirow[b]{2}{*}{ Model } & \multicolumn{3}{|c|}{ T1 } & \multicolumn{3}{|c|}{ T2 } & \multicolumn{3}{|c|}{ T3 } \\
\hline & & $\begin{array}{c}K_{m p: f p} \\
(\mathrm{~mL} / \mathrm{min})\end{array}$ & $\begin{array}{l}A U C_{24 f e t} \\
(\mathrm{mg.h} / \mathrm{L})\end{array}$ & $\begin{array}{l}\operatorname{Cmax}_{\text {fet }} \\
(\mathrm{mg} / \mathrm{L})\end{array}$ & $\begin{array}{c}K_{m p: f p} \\
(\mathrm{~mL} / \mathrm{min})\end{array}$ & $\begin{array}{l}A U C_{24 f e t} \\
(\mathrm{mg} . \mathrm{h} / \mathrm{L})\end{array}$ & $\begin{array}{l}\operatorname{Cmax}_{\text {fet }} \\
(\mathrm{mg} / \mathrm{L})\end{array}$ & $\begin{array}{c}K_{m p: f p} \\
(\mathrm{~mL} / \mathrm{min})\end{array}$ & $\begin{array}{l}A U C_{24 f e t} \\
(\mathrm{mg} . \mathrm{h} / \mathrm{L})\end{array}$ & $\begin{array}{l}\operatorname{Cmax}_{\text {fet }} \\
(\mathrm{mg} / \mathrm{L})\end{array}$ \\
\hline \multirow[t]{4}{*}{ THEO } & $S E$ & 2 & 2540 & 2.95 & 7.2 & 2747 & 2.47 & 14.6 & 3013 & 2.54 \\
\hline & $\operatorname{In} V$ & 25.2 & 2612 & 4.02 & 89.6 & 3238 & 3.83 & 181.7 & 3777 & 4.16 \\
\hline & $P L$ & - & 2615 & 4.14 & - & 3265 & 4.44 & - & 3830 & 4.72 \\
\hline & $E x V$ & $0.4^{a}$ & 2920 & 2.61 & $1.4^{\alpha}$ & 1968 & 1.64 & $2.3^{a}$ & 1579 & 1.43 \\
\hline \multirow[t]{4}{*}{ NEVI } & $S E$ & 0.8 & 1732 & 1.63 & 2.8 & 1598 & 1.29 & 5.6 & 1619 & 1.26 \\
\hline & $\operatorname{In} V$ & 22.6 & 1968 & 3.69 & 80.4 & 2328 & 3.05 & 163 & 2706 & 3.19 \\
\hline & $P L$ & - & 1973 & 3.91 & - & 2348 & 4.40 & - & 2742 & 4.91 \\
\hline & $E x V$ & $0.5^{\beta}$ & 1849 & 1.74 & $2^{\beta}$ & 1632 & 1.34 & $3.2^{\beta}$ & 1364 & 1.15 \\
\hline \multirow[t]{4}{*}{$\overline{D Z P}$} & $S E$ & 6.3 & 34 & 0.04 & 22.6 & 42 & 0.03 & 45.7 & 48 & 0.04 \\
\hline & $\operatorname{In} V$ & 48 & 44 & 0.11 & 170.7 & 70 & 0.08 & 346 & 91 & 0.08 \\
\hline & $P L$ & - & 45 & 0.19 & - & 78 & 0.31 & - & 112 & 0.40 \\
\hline & $E x V$ & $7.1^{\gamma}$ & 29 & 0.03 & $28.9^{\gamma}$ & 11 & 0.01 & $46.9^{\gamma}$ & 7 & 0.01 \\
\hline
\end{tabular}

${ }^{\alpha} K_{f p: m p}=0.3(\mathrm{~T} 1), 1.2(\mathrm{~T} 2), 1.9(\mathrm{~T} 3) \mathrm{mL} / \mathrm{min} ;{ }^{\beta} K_{f p: m p}=0.5(\mathrm{~T} 1), 2(\mathrm{~T} 2), 3.3(\mathrm{~T} 3) \mathrm{mL} / \mathrm{min} ;{ }^{\gamma} K_{f p: m p}=0.02(\mathrm{~T} 1), 0.06(\mathrm{~T} 2), 0.1(\mathrm{~T} 3) \mathrm{mL} / \mathrm{min}$. 
Marc Codaccioni: Conceptualization, Methodology, Software, Writing - Original Draft

Céline Brochot: Conceptualization, Methodology, Validation, Writing - Reviewing and Editing 


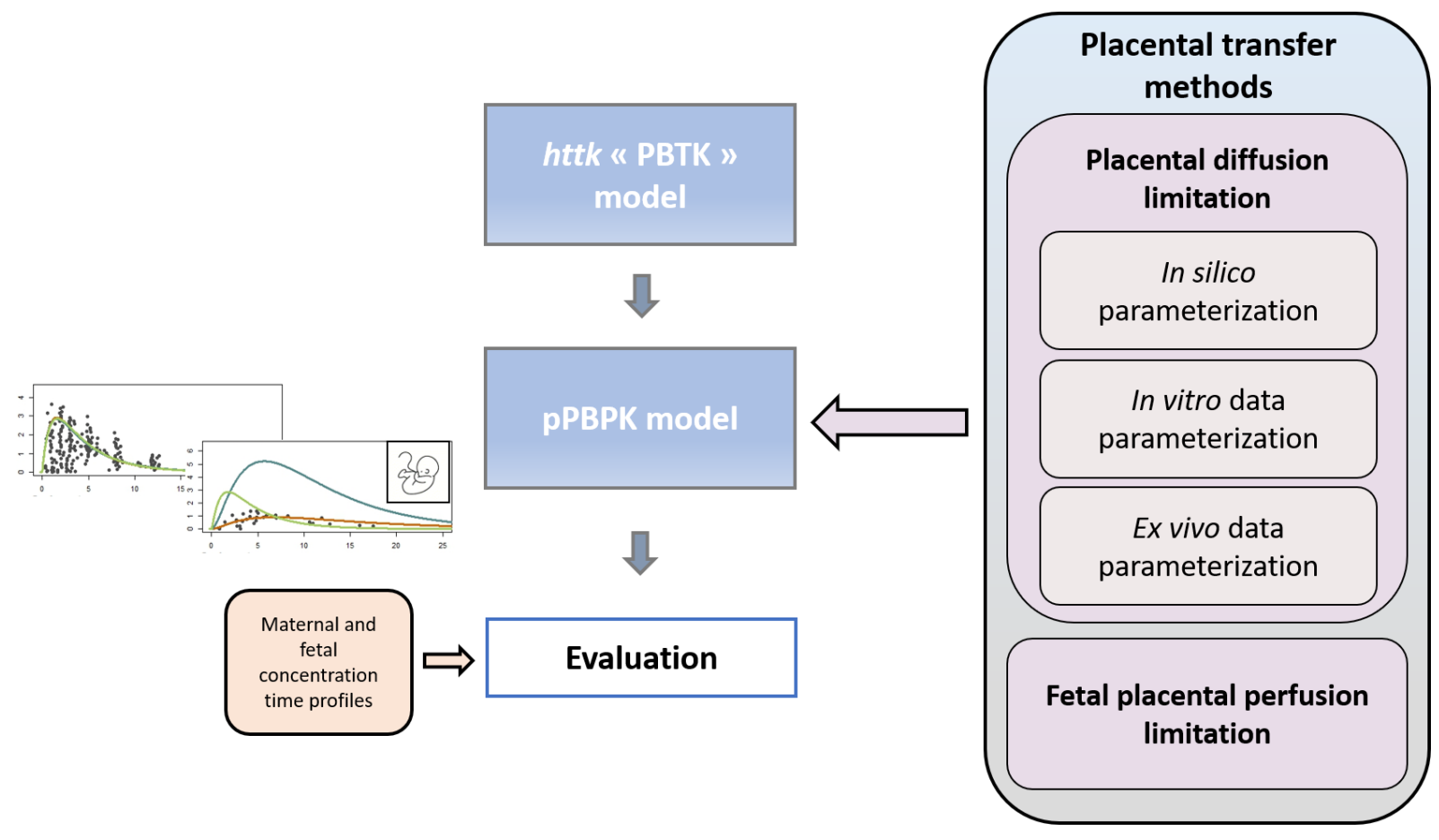

Graphical abstract: Workflow of the pPBPK model development and placental transfer models evaluation. 


\section{Declaration of interests}

$\bigotimes$ The authors declare that they have no known competing financial interests or personal relationships that could have appeared to influence the work reported in this paper.

$\square$ The authors declare the following financial interests/personal relationships which may be considered as potential competing interests:

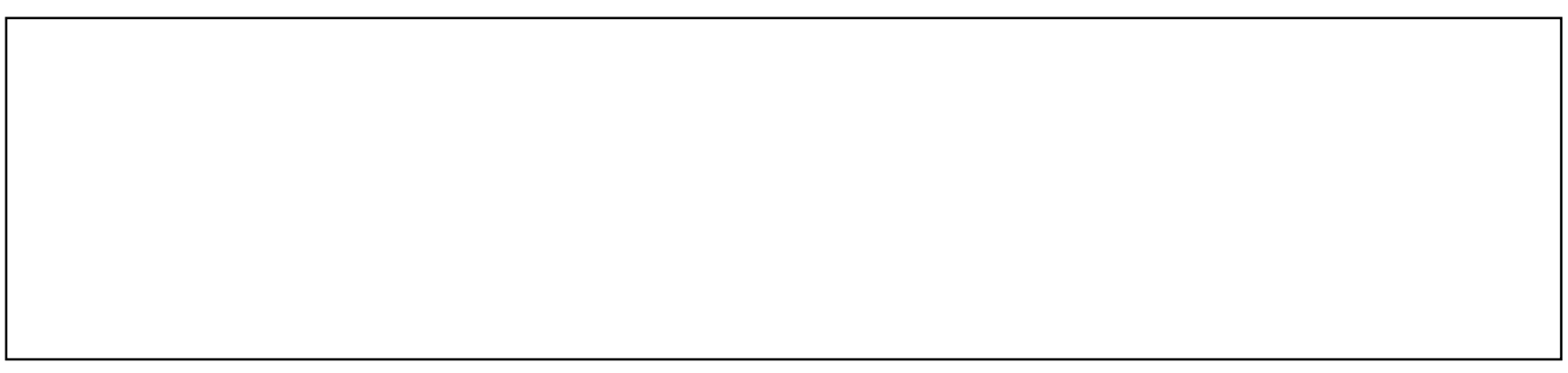


$\checkmark$ We developed a pPBPK model for human and assessed its predictions on 10 compounds

$\checkmark$ Four placental transfer models were tested and calibrated with non-animal methods

$\checkmark$ The four transfer models provided different pharmacokinetic profiles in the fetus

$\checkmark$ In late pregnancy, models with rapid diffusion to the fetus had the best performance

$\checkmark$ All models but one predicted the highest fetal exposure at the end of pregnancy 